\title{
Variation Law of Infrared Radiation Temperature of Unloading Fracture of Composite Coal-Rock
}

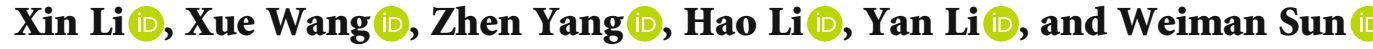 \\ Faculty of Electrical and Control Engineering, Liaoning Technical University, Huludao 125105, China \\ Correspondence should be addressed to Xue Wang; 1016238726@qq.com
}

Received 1 June 2021; Accepted 16 July 2021; Published 14 August 2021

Academic Editor: Feng Du

Copyright () 2021 Xin Li et al. This is an open access article distributed under the Creative Commons Attribution License, which permits unrestricted use, distribution, and reproduction in any medium, provided the original work is properly cited.

\begin{abstract}
For composite mining coal-rock dynamic disaster, combining the theory of thermodynamics, damage mechanics, and other disciplines, the thermodynamic coupling mathematical model of composite coal-rock under an unloading condition is deduced, and the simulation model of composite coal-rock is established for numerical simulation. And the variation law of thermal infrared radiation under triaxial loading and unloading of composite coal-rock is analyzed and verified by experiments. The results show the following findings: (1) The distribution of thermal infrared radiation temperature of composite coal-rock is different in different stages of stress. The overall temperature of the temperature field is lower than the initial temperature field in the threedimensional stress loading stage and the stage of stress-keeping pressure, but the internal temperature of the coal body is the highest. In the first stage of "loading and unloading," the temperature of a coal seam increases slightly, and the temperature of other parts of the rock layer increases except for the circular low-temperature zone. In the second stage of "loading and unloading," an alternating zone of high and low temperatures appears in the rock mass, and the temperature field is enhanced, among which the temperature field reaches the strongest after unloading the confining pressure. After jumping over the maximum stress, the temperature field decreases as a whole at the instability and rupture stage. (2) The variation of surface average thermal infrared radiation temperature $\left(T_{\text {ave }}\right)$ of composite coal-rock can be divided into the initial fluctuation stage, the linear heating stage, the local decline stage, the temperature sudden increase stage, and the fracture decline stage. At three different unloading rates of $0.003 \mathrm{MPa} / \mathrm{s}, 0.03 \mathrm{MPa} / \mathrm{s}$, and $0.05 \mathrm{MPa} / \mathrm{s}$, the $T_{\text {ave }}$ of coal body, floor rock, and roof rock reach the maximum before composite coal-rock instability and fracture, and the temperature change of the coal body is the most obvious. (3) Under different confining pressure unloading rates, the $T_{\text {ave }}$ of roof rock, coal body, and floor rock shows a strong linear relationship with stress after linear fitting. And the correlation between simulation and experimental results after fitting is above 0.89 . The larger the confining pressure unloading rate is, the shorter the peak time of $T_{\text {ave }}$ arrives, and the larger the peak value. The comparison between the experimental results and the simulation analysis shows that the two results are consistent, and the research results can provide a theoretical basis for the prevention and control of dynamic disasters in coal and rock mining.
\end{abstract}

\section{Introduction}

With the increasing depth of coal mining, coal and rock dynamic disasters such as coal and gas outburst and rock burst are becoming more and more serious [1]. Reference [2] shows that nearly half of coal mine disasters in China have been found to occur in groups or accompanied by nearby earthquakes, and all types of disasters are involved. The stress disturbance appears to exist between mining areas. The process of coal mining is an unloading process essentially. This mechanical process will cause a lot of thermal infrared radiation and temperature change in coal and rock mass [3-6]. At the same time, the temperature change during the mining process will further affect the physical parameters and mechanical properties of the material, thus making the actual unloading process more complex. At present, most studies on the mechanical properties of coal and rock are carried out under uniaxial loading conditions. Reference [7] studied the brittle failure model of coal-rock composites under uniaxial compression through laboratory tests and numerical simulation. Reference [8] analyzed stress characteristics and mechanical properties and compared the similarities and differences of composite coal mass with soft 
and hard coal mass in deformation and failure characteristics. Moreover, the mechanical properties and deformation and failure laws of the composite coal mass under unidirectional loading were investigated. Reference [9] studied the mechanical properties of coal-like rocks and the law of damage evolution under different loading rates. The results show that the higher the loading rate, the earlier the specimen enters the stage of stable development of damage. In [10], the particle flow method was used to establish the composite model of coal and rock with different inclination angles, and the impact instability characteristics after unloading were analyzed.

Relevant results at home and abroad show that by studying the distribution and variation rule of thermal infrared radiation in composite coal-rock, the dynamic disaster of coal and rock can be effectively predicted [11-14]. Reference $[15,16]$ used an infrared thermal imager to conduct a simulation test on the failure process of rock strata caused by excavation, and found that infrared radiation temperature can reflect the change of rock strata stress at different depths, while an infrared thermal image can reflect the failure process of rock mass. Reference [17] believes that infrared precursors are mainly manifested as infrared thermography and average infrared radiation temperature anomaly. Reference [18] carried out the infrared radiation observation test on the stress disaster of granite, studied the mechanism of the infrared anomaly phenomenon before the earthquake, and found that the infrared radiation temperature on the outer surface of the rock also changed with the constant change of the stress. Reference [19] carried out uniaxial compression loading tests on aqueous concrete samples, and tested and studied the variation characteristics of infrared radiation temperature, infrared thermography, and acoustic emission, as well as the precursor information of fracture. Reference [20] used infrared thermal imaging technology to study the changes in infrared radiation during coal-rock deformation. The research showed that the infrared radiation temperature on the coal and rock surface would be changed with the increase of the loadings. There was a stage differential in infrared radiation temperature variation in the cracking-developed zone, stress-concentrated area, and broken zone. Reference [21] carried out an observation test of infrared radiation characteristics in the process of loading failure of coal samples, discussed the infrared precursor information of instability failure of coal samples with different bursting liabilities, and obtained the infrared radiation temperature precursor characteristics of coal samples under the condition of no flushing, weak flushing, and strong flushing. Reference [22] monitored the change of an infrared radiation temperature field in surrounding rock of a roadway through infrared radiation technology, and verified that the radiation temperature field had a good corresponding relationship with roadway failure characteristics. Reference [23] found that infrared radiation changes would occur along with stress adjustment in the process of mechanical fracture of coal and rock. Reference [24] quantitatively analyzed the characteristic parameters of infrared radiation temperature and the evolution law of coal and rock damage in the process of coal and rock loading. Reference [25] studied the internal infrared radiation temperature change law of composite coalrock under load. The results show that the composite coalrock has thermoelastic effects and thermal friction effects during the loading process. In addition, the heat generated by the displacement and friction between the fissure surfaces of the coal is significantly higher than the heat generated by the thermoelastic effect, and the thermoelastic effect in the rock mass plays a leading role. Reference [26] found that the thermal infrared radiation temperature temporal evolution in the process of a fracture of coal and rock can be divided into four stages, namely, the $T_{\text {ave }}$ calm stage, the $T_{\text {ave }}$ slight fluctuation stage, the $T_{\text {ave }}$ rapid increase stage, and the $T_{\text {ave }}$ rapid decrease stage, which accurately described the infrared radiation law of coal and rock under uniaxial loading and unloading state. Reference [27] found in their study that the infrared radiation precursor of coal-rock fracture and instability showed a trend of step and type spurt upward. In summary, predecessors have studied the characteristics of thermal infrared radiation temperature and precursor laws of coal and rock under uniaxial loading, but there are few related studies on unloading failure of deep coal and rock mass.

Based on the above research results, related scholars have carried out related research on unloading fracture of coal and rock and multifield coupling research. However, there are few studies on the thermal-mechanical coupling mechanism of anisotropic coal and rock masses, and the research on thermal infrared radiation under the condition of triaxial unloading of composite coal-rock is not thorough enough. Reference [28] conducted a three-axis unloading compression test based on the pressure path of the underground engineering excavation. The research results show that the infrared radiation characteristics of rock specimens under different intermediate principal stresses are different, revealing that as the intermediate principal pressure increases, the failure mode of the rock is also different. Reference [29] conducted conventional triaxial compression (CTC) tests on the gas-bearing coal, gas-bearing coal-mudstone combination, and gas-bearing coal-sandstone combination using the RLW-500G triaxial experimental system. Reference [30] conducted laboratory tests under two stress paths, namely, conventional triaxial compression and prepeak unloading confining pressure, in order to explore the failure mechanism of the unloading side of coal roadway excavation, and analyzed its mechanical characteristics. According to the damage and failure law, the results show that under the unloading stress path, the coal body failure is a composite state in which shear failure is the main part, but there is still partial split failure. Based on the unloading mechanics path of the fixed axial displacement and the unloading surrounding pressure, the study on the damage features during the unloading process was conducted on the reconstituted coal with high plasticity with $\mathrm{CT}$ value, CT damage, and $\mathrm{CT}$ image of each scanning layer obtained from CT imaging experiments [31]. Reference [32] established a temperature-stress numerical coupling model of rock at high temperature, carried out numerical simulation on the evolution law of the temperature field and fracture field of overburden rock in a combustion cavity under the temperature-stress coupling condition, and studied the 
relationship between stress and temperature in the state of rock thermal damage. Reference [33] carried out physical experiments and numerical simulations on the system instability faults of gas coal-bearing rock under different circumstances, comprehensively analyzed the multiphysical coupling mechanism of gas coal-bearing rock damage and the occurrence conditions of outbreak-rock coupling dynamic disaster, and improved the understanding of the mechanism of outbreakrock coupling dynamic disaster. Reference [34] conducted an unloading coal and rock destruction experiment under the multiphase coupling action of water, force, and heat. By optimizing the noise reduction and the infrared radiation information of three-dimensional fusion, the three-dimensional infrared radiation field was reconstructed. And by considering the surface damage characteristics, the three-dimensional infrared radiation field and simulation software results reveal the spatiotemporal evolution of the infrared radiation information of the unloading damage of composite coal-rock, and realize the noncontact prediction of coal and rock dynamic disasters. Reference [35] proposed a thermal-mechanical coupling method for large-volume concrete on the inner wall of deep wells, considering various boundary conditions such as internal heat source, external cold source, plastic plate friction constraint, overlying shaft wall load, and formation lateral pressure. The early temperature-stress field evolution characteristics of the inner wall of the deep frozen wellbore were obtained, and the high-risk areas prone to early temperature cracks were determined. The abovementioned research results have made a very useful exploration of thermal infrared radiation precursors before unloading and rupture of coal and rock, and laid the foundation for subsequent research.

In summary, a large number of coal and rock mining dynamic disaster events show that before the occurrence of dynamic disaster events, there will be various degrees of precursor information, such as changes in stress and strain, temperature, and acoustic emission. By monitoring the changing trends and abnormal values of these signals, it is possible to provide effective early warning of shock disaster hazards, and timely effective control measures can be taken to reduce the casualties and equipment damage caused by rock shock disasters, which has engineering application prospects. However, most of the current researches on the prediction and prediction of coal and rock mining dynamic disasters are based on uniaxial conditions, which is far from the actual three-axis mining situation. The research on the infrared radiation temperature law based on the three-axis unloading condition needs to be in-depth. There is still much room for improvement in analyzing the unloading rupture mechanism from the perspective of multiphysics coupling. There are few studies on the thermodynamics of anisotropic coal and rock masses. Aiming at the problem of effectively predicting and forecasting coal and rock mining dynamic disasters, this paper intends to study not only the distribution of thermal infrared radiation temperature during the unloading and fracture process of anisotropic composite coal-rock, but also the relationship between thermal infrared radiation and stress on the surface of composite coal-rock and its changing law based on thermodynamics and damage mechanics. Joint early-warning simulations and experiments on coal and rock instability through multiphysics fields to explore the characteristics of infrared radiation temperature changes and coal and rock rupture precursor laws have important theoretical significance for the development of coal and rock mining dynamic disaster prediction and forecast.

\section{Materials and Methods}

2.1. Thermal-Mechanical Coupling Model of Composite CoalRock Unloading. According to the Stefan-Boltzman Law, the thermal infrared radiation energy of the coal and rock surface is proportional to the power of the physical temperature and emittance. When the material type and surface finish of coalrock are constant, the thermal infrared radiation intensity received by the surface is only related to the physical temperature of coal-rock [26]. Therefore, during the loading-unloading process, when the thermal infrared radiation intensity of the composite coal-rock under the action of stress changes, the reason is that the external stress causes the change of the thermal field of the coal-rock, which leads to the alienation of the temperature field of thermal infrared radiation on the surface of the coal-rock. This thermal change is actually a thermodynamic coupling effect, in which the thermal stress will produce thermal damage and other effects and accelerate the instability failure of the coal and rock mass [36].

According to the Elastic Damage Theory, the equivalent elastic modulus $E$ of coal-rock after damage can be expressed as follows:

$$
E=(1-D) E_{0}
$$

where $E_{0}$ is the initial elastic modulus before damage; $D$ is the damage variable, which is used to describe the damage degree and evolution of coal-rock under the action of external load.

Taking the interior elements of coal and rock mass as the research object, the magnitude of the three principal stresses in the loading-unloading process is not zero [37], which conforms to the generalized Hooke law on the whole. The principal strain equation is as follows:

$$
\left\{\begin{array}{l}
\varepsilon_{x}=\frac{1}{E}\left[\sigma_{x}-\mu\left(\sigma_{y}+\sigma_{z}\right)\right], \\
\varepsilon_{y}=\frac{1}{E}\left[\sigma_{y}-\mu\left(\sigma_{x}+\sigma_{z}\right)\right], \\
\varepsilon_{z}=\frac{1}{E}\left[\sigma_{z}-\mu\left(\sigma_{x}+\sigma_{y}\right)\right],
\end{array}\right.
$$

where $\varepsilon_{i}(i=x, y, z)$ is the principal strain; $E$ is the elastic modulus; $\sigma_{i}(i=x, y, z)$ is the principal stress; $\mu$ is the Poisson ratio.

The shear strain equation is as follows:

$$
\left\{\begin{array}{l}
\gamma_{x y}=\frac{1}{G} \tau_{x y}=\frac{2(1+\mu)}{E} \tau_{x y}, \\
\gamma_{y z}=\frac{1}{G} \tau_{y z}=\frac{2(1+\mu)}{E} \tau_{y z}, \\
\gamma_{z x}=\frac{1}{G} \tau_{z x}=\frac{2(1+\mu)}{E} \tau_{z x},
\end{array}\right.
$$


where $\gamma_{i i}(i i=x y, y z, z x)$ is the shear stress; $\tau_{i i}(i i=x y, y z, z x)$ is the shear strain; $G=E /(2(1+\mu))$ is the Lame constant.

Equation (2) and equation (3) jointly express the stressstrain relationship of composite coal-rock under unloading conditions. In a three-dimensional elastic system, strain can be characterized by principal strain and shear strain components. According to the principles of thermodynamics and reference [38], the relationship between temperature changes and strains of each component of the composite coal-rock is further deduced as follows:

$$
\Delta T=\frac{T_{0} V}{C}\left(\sum \beta \varepsilon_{i}+\sum \beta \tau_{i i}\right),
$$

where $T_{0}$ is the initial temperature of different components of the composite coal-rock $\left({ }^{\circ} \mathrm{C}\right) ; \mathrm{V}$ is the volume of the different components of the composite coal-rock $\left(\mathrm{m}^{3}\right)$; $C$ is the specific heat capacity of the different components of the composite coal-rock $(\mathrm{J} /(\mathrm{kg} \cdot \mathrm{K})) ; \beta=\left(\partial \sigma_{i} / \partial T_{0}\right)_{\varepsilon},(i=x, y, z)$ or $\left(\partial \tau_{i i} / \partial T_{0}\right)_{\varepsilon},(i i=x y, y z, z x)$ is the thermal stress coefficient.

Then, the temperature field $T$ of different components of composite coal-rock at any time is as follows:

$$
T=T_{0}+\Delta T \text {. }
$$

Substitute equation (1), equation (2), and equation (3) into equation (4). And according to equation (5), the specific relationship between temperature field and strain of each component of composite coal-rock can be obtained as follows:

$$
\begin{aligned}
T=T_{0}\{ & \left(1+\frac{V}{C}\right)\left[\frac{(1-2 \mu)}{(1-D) E_{0}}\left(\beta_{x} \sigma_{x}+\beta_{y} \sigma_{y}+\beta_{z} \sigma_{z}\right)\right. \\
& \left.\left.+\frac{(1-D) E_{0}}{(1-2 \mu)}\left(\beta_{x y} \sigma_{x y}+\beta_{y z} \sigma_{y z}+\beta_{z x} \sigma_{z x}\right)\right]\right\} .
\end{aligned}
$$

In order to establish the thermodynamic coupling model, the heat conduction equation should be added to determine the distribution of temperature field $T$ in composite coalrock. According to the principle of heat balance in thermodynamics, it is assumed that the specific heat capacity $C$ and thermal conductivity $\lambda_{i}(i=x, y, z)$ of composite coal-rock are constants that do not change with temperature. Introduce the solid three-dimensional anisotropic heat conduction differential equation [39] to describe the internal temperature field of composite coal-rock. The specific differential equation is as follows:

$$
\frac{\partial T}{\partial t}=\frac{f(t)}{\rho C}\left[\frac{\partial}{\partial x}\left(\lambda_{x} \frac{\partial T}{\partial x}\right)+\frac{\partial}{\partial y}\left(\lambda_{y} \frac{\partial T}{\partial y}\right)+\frac{\partial}{\partial z}\left(\lambda_{z} \frac{\partial T}{\partial z}\right)\right]
$$

where $\rho$ is the density of material $\left(\mathrm{kg} / \mathrm{m}^{3}\right) ; \lambda_{x}, \lambda_{y}$, and $\lambda_{z}$ are the thermal conductivity coefficients of the material in three directions $(\mathrm{W} /(\mathrm{m} \cdot \mathrm{K})) ; f(t)$ is the rate of heat release.

However, when coal and rock are damaged under external force, the damage will lead to the increase of thermal conductivity and specific heat capacity of coal-rock. It is assumed that the influence of damage $D$ on the specific heat capacity $C$ and thermal conductivity $\lambda_{i}(i=x, y, z)$ of composite coalrock meets the following functional relationship [40]:

$$
\begin{aligned}
& C=C_{0} e^{D / \alpha_{\lambda_{i}}}, \\
& \lambda_{i}=\lambda_{0} e^{D / \alpha_{\lambda_{i}}},
\end{aligned}
$$

where $C_{0}$ and $C$ are the specific heat capacity of composite coal-rock of different components before and after damage $(\mathrm{J} /(\mathrm{kg} \cdot \mathrm{K})) . \lambda_{0}$ and $\lambda_{i}(i=x, y, z)$ are the thermal conductivity before and after damage of coal and rock of different components $(\mathrm{W} /(\mathrm{m} \cdot \mathrm{K})) . \alpha_{C}$ and $\alpha_{\lambda i}$ are the influence coefficients of damage on the specific heat capacity and thermal conductivity of different components of composite coal-rock, respectively.

By substituting equation (8) into equation (6) and equation (7), the temperature of different components of composite coal-rock and the instantaneous temperature of each point in coal and rock can be calculated. The average infrared radiation temperature $\left(T_{\text {ave }}\right)$ refers to the average value of the infrared radiation temperature corresponding to each point on the coal and rock surface at a certain moment, which reflects the variation characteristics of the infrared radiation temperature field on the coal and rock surface on the whole [25]. The specific equation is as follows:

$$
T_{\text {ave }}=\frac{1}{n} \sum_{i=1}^{n} T_{i},
$$

where $T_{i}$ is the radiation temperature of the $i$ th point in the temperature field $\left({ }^{\circ} \mathrm{C}\right) . T_{\text {ave }}$ is the average of $T_{i}\left({ }^{\circ} \mathrm{C}\right) . n$ is the number of selected composite coal-rock points.

To sum up, the coupling mathematical model of the thermal infrared radiation temperature field and the stress field in the process of unloading and fracture of composite coal-rock is as follows:

$$
\left\{\begin{array}{l}
T=T_{0}\left\{\left(1+\frac{V}{C_{0} e^{D / \alpha_{C}}}\right)\left[\frac{(1-2 \mu)}{(1-D) E_{0}}\left(\beta_{x} \sigma_{x}+\beta_{y} \sigma_{y}+\beta_{z} \sigma_{z}\right)+\frac{(1-D) E_{0}}{(1-2 \mu)}\left(\beta_{x y} \sigma_{x y}+\beta_{y z} \sigma_{y z}+\beta_{z x} \sigma_{z x}\right)\right]\right. \\
\frac{\partial T}{\partial t}=\frac{\lambda_{0} f(t)}{\rho C_{0} e^{D / \alpha_{C}}}\left[\frac{\partial}{\partial x}\left(e^{\frac{D}{\alpha_{x}}} \frac{\partial T}{\partial x}\right)+\frac{\partial}{\partial y}\left(e^{\frac{D}{\lambda_{y}}} \frac{\partial T}{\partial y}\right)+\frac{\partial}{\partial z}\left(e^{\frac{D}{\alpha_{z}}} \frac{\partial T}{\partial z}\right)\right], \\
T_{\text {ave }}=\frac{1}{n} \sum_{i=1}^{n} T_{i} .
\end{array}\right.
$$


2.2. Simulation Model of Composite Coal-Rock Unloading. FLAC $^{3 \mathrm{D}}$ software is used to establish a standard cylindrical composite coal-rock 3D model with the size of $\Phi 50 \mathrm{~mm} \times$ $100 \mathrm{~mm}$. The ratio of component rock-coal-rock is $1: 1: 1$. The physical parameters of the top slate and the bottom slate in the model are the same. The model is generally divided into 79200 units and 80,581 nodes. The constitutive relation of the three-dimensional composite coal-rock model in the mechanical mode is set as the commonly used Mohr-Coulomb Plastic Model [41], and the constitutive model in the thermal mode is the anisotropic heat conduction model. The material property parameters of the simulation model are shown in Table 1.

According to the "Coal Mine Safety Regulations," the working surface temperature does not exceed $26^{\circ} \mathrm{C}$ [42], and the temperature conditions are those that can be achieved by indoor experiments. Set the initial temperature and ambient temperature of the composite coal-rock simulation model in thermal mode to room temperature $20^{\circ} \mathrm{C}$. The steps of the three-axial load-unloading simulation in the mechanical mode are as follows: (1) Apply fixed constraints and axial stress to the top and bottom of the model, and apply $10 \mathrm{MPa}$ confining pressure. (2) Keep the confining pressure constant, and load at a displacement rate of $0.05 \mathrm{~mm} / \mathrm{min}$. (3) Record the stress loading curve until the composite coal-rock fracture, and record the peak stress intensity. (4) Under the simulation conditions in steps (1) and (2), triaxial loading is carried out again. When the stress reaches $80 \%$ of the peak intensity recorded in step (3), under the condition of ensuring that the simulation results are not distorted, three commonly used slow unloading confining pressure rates of $0.003 \mathrm{MPa} / \mathrm{s}, 0.03 \mathrm{MPa} / \mathrm{s}$, and $0.05 \mathrm{MPa} / \mathrm{s}[43,44]$ are selected for unloading simulation until the composite coal and rock rupture, and the simulation ends.

\section{Results and Discussion}

\subsection{Simulation Research}

3.1.1. Distribution Law of Thermal Infrared Radiation Temperature. In order to better study the relationship between the unloading fracture mechanics stage of coal-rock and its infrared radiation temperature, the stress change process must first be clarified. The stress-time $(\sigma-t)$ curve of triaxial loadingunloading under the unloading rate of $0.05 \mathrm{MPa} / \mathrm{s}$ confining pressure is shown in Figure 1. It is divided into five stages. $\mathrm{OA}$ is the three-dimensional stress loading stage. At this stage, due to the combined action of axial pressure and confining pressure, the primary voids and tiny cracks in the composite coal are gradually compacted, and the internal structure begins to change. This stage is similar to the compaction stage in uniaxial loading. $\mathrm{AB}$ is the stage of stress-keeping pressure. This stage is a process in which the axial pressure and the confining pressure resist each other, and the axial pressure presents a nonlinear change. BC is the first stage of "loadingunloading," which is elastic. The stress shows a linear increase trend. CD is the second stage of "loading-unloading," which is the process of converting elasticity to plasticity. The stress at this stage shows a transition from linear to nonlinear. DE is the instability and rupture stage. After unloading the confining
TABle 1: Physical parameters of materials.

\begin{tabular}{lcc}
\hline Physical parameters & Coal & Rock \\
\hline Bulk modulus $(\mathrm{GPa})$ & 1 & 4.5 \\
Shear modulus $(\mathrm{GPa})$ & 0.8 & 3 \\
Cohesion $(\mathrm{MPa})$ & 1 & 2.5 \\
Tensile strength $(\mathrm{MPa})$ & 1 & 2 \\
Density $\left(\mathrm{kg} / \mathrm{m}^{3}\right)$ & 1450 & 2400 \\
Specific heat capacity $(\mathrm{J} /(\mathrm{kg} \cdot \mathrm{K}))$ & 1200 & 920 \\
Thermal expansion coefficient $\left({ }^{\circ} \mathrm{C}\right)$ & $6.435 \times 10^{-6}$ & $3.9 \times 10^{-5}$ \\
Thermal conductivity $(\mathrm{W} /(\mathrm{m} \cdot \mathrm{K}))$ & 0.258 & 3.081 \\
\hline
\end{tabular}

pressure at a rate of $0.05 \mathrm{MPa} / \mathrm{s}$ at $142.5 \mathrm{~s}$, until the peak stress at point $\mathrm{D}$ reaches the maximum value of $45.45 \mathrm{MPa}$, the composite coal-rock fractures, the curve drops rapidly, and the simulation ends.

In the simulation process, there is no need to slice the composite coal-rock simulation model, that is, the distribution of $T_{\text {ave }}$ can be observed through the overall infrared radiation temperature distribution cloud map. Figure 2 is a cloud map of the overall infrared radiation temperature distribution of the composite coal-rock under the confining pressure unloading at a rate of $0.05 \mathrm{MPa} / \mathrm{s}$. At each stage of stress and after unloading the confining pressure, a time point is selected for analysis at $25 \mathrm{~s}, 60 \mathrm{~s}, 90 \mathrm{~s}, 130 \mathrm{~s}, 146 \mathrm{~s}$, and $175 \mathrm{~s}$, respectively. It can be seen from Figure 2 that the temperature distribution is different at different stages. However, due to the coal body's low density and low thermal conductivity, it has a large degree of force deformation and high-temperature accumulation. But the coal body has slow heat transfer and small temperature changes, and finally presents the characteristics of hightemperature distribution in the coal body.

From the perspective of different stages, the overall temperature of the temperature field during the three-dimensional stress loading (Figure 2(a)) and stress-keeping pressure stage (Figure 2(b)) is lower than the initial temperature. In the first stage of "loading-unloading" (Figure 2(c)), as the effect of axial stress becomes more obvious, the temperature of the coal body rises slightly. Except for the circular low-temperature zone, the temperature of the rest of the rock formation increases. In the second stage of "loading-unloading" (Figure 2(d)), the hightemperature area of the coal body spreads up and down on both sides of the rock mass. And the temperature field of part of the rock mass is significantly enhanced compared with the previous stage, and there is an alternating phenomenon of high- and lowtemperature regions in the lateral direction. After the confining pressure is relieved (Figure 2(e)), the temperature distribution of the temperature field expands according to the trend of the previous stage, and the temperature field reaches the strongest. After jumping over the highest point of stress, the coal-rock loses stability and ruptures, and the temperature field decreases during the instability and rupture stage (Figure 2(f)).

\subsubsection{Changes of Thermal Infrared Radiation Temperature and Stress}

(1) Study on Different Unloading Confining Pressure Rates. Figure 3 shows the stress-time $(\sigma-t)$ curve of composite 


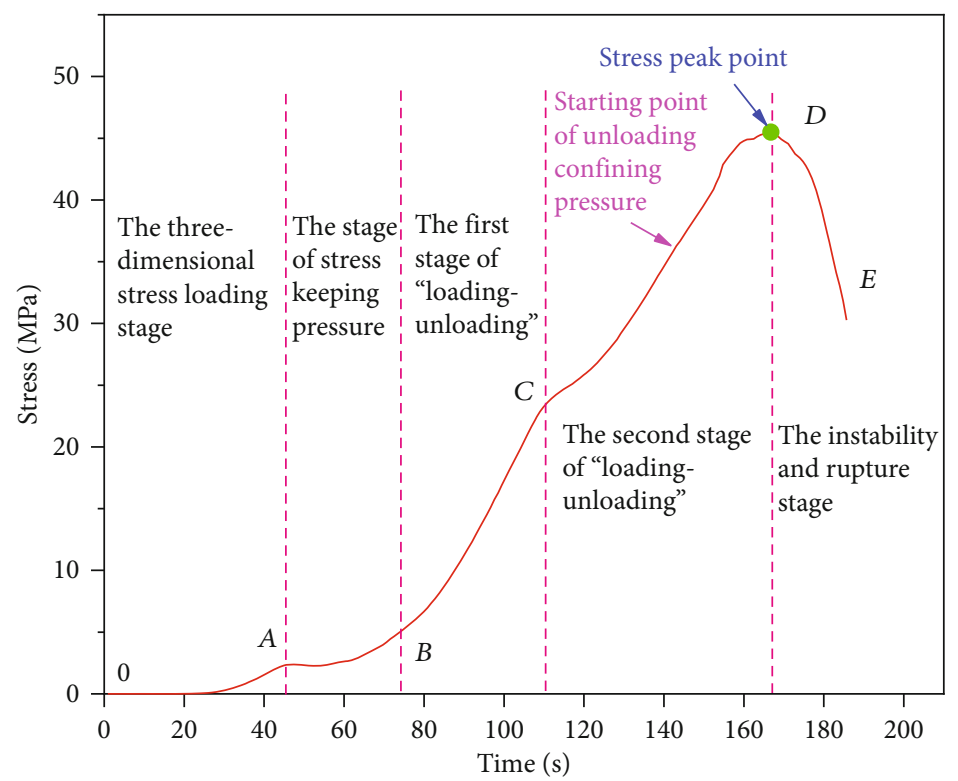

Figure 1: The stress-time curve of compound coal-rock. The confining pressure is set to $10 \mathrm{MPa}$, the unloading rate is $0.05 \mathrm{MPa} / \mathrm{s}$, and $D$ is the stress peak point. The three-axis loading and unloading of composite coal-rock is divided into five stages.

coal-rock triaxial loading-unloading simulation under different unloading confining pressure rates. By comparison, when the confining pressure and other conditions are the same and only the unloading rate is changed, the stress stages remain unchanged, and can still be divided into five stages. The overall stress trend is the same, and the previous loading curves are completely coincident. However, with the increase of unloading rate, the stress peak point of composite coal-rock fracture is reduced, the time from loading to fracture becomes shorter, and the overall stiffness and strength of composite coal-rock decreases, making it easier to fracture.

It can be seen from the foregoing that $T_{\text {ave }}$ can reflect the average radiation intensity of the infrared radiation released from the surface of the composite coal-rock, so this paper uses $T_{\text {ave }}$ as the analysis parameter for research. Figure 4 shows the average thermal infrared radiation temperature-time $\left(T_{\text {ave }}-t\right)$ curve of the coal surface under the condition of different rates of unloading confining pressure. It can be seen from Figure 4 that the three curves start to change from $142.5 \mathrm{~s}$ after unloading. And the peak arrival time of $T_{\text {ave }}$ at $0.05 \mathrm{MPa} / \mathrm{s}$ unloading confining pressure is earlier than that at $0.03 \mathrm{MPa} / \mathrm{s}$ and $0.003 \mathrm{MPa} / \mathrm{s}$ unloading confining pressure. The peak temperature is $22.49^{\circ} \mathrm{C}$, which is greater than the $22.28^{\circ} \mathrm{C}$ and $22.03^{\circ} \mathrm{C}$ of the latter two. That is to say, under the same conditions, the greater the confining pressure unloading rate, the shorter peak time of $T_{\text {ave }}$ and the greater the peak value.

(2) The Law of Thermal Infrared Radiation Temperature Change. Figure 5 shows the $T_{\text {ave }}-\sigma$ - $t$ curves of different components of composite coal-rock under the above three different confining pressure unloading rates, and the trends of the three are consistent. According to the average thermal infrared radiation temperature change curve of the coal surface, the temperature change process is divided into five stages: the initial fluctuation stage, the linear heating stage, the local decline stage, the temperature sudden increase stage, and the fracture decline stage. Take Figure $5(\mathrm{c})$ as an example for analysis. The five stages are as follows:

(1) Initial fluctuation stage: $T_{\text {ave }}$ of different components of composite coal-rock shows a fluctuating trend of decreasing, increasing, and then decreasing to varying degrees. The difference is that the wave peak of the coal body appears later than the floor rock and the roof rock in sequence, and the $T_{\text {ave }}$ fluctuation degree is larger, and the maximum fluctuation is $0.38^{\circ} \mathrm{C}$. At the same time, combined with Figure 1, it can be seen that, compared with the three-dimensional stress loading stage (OA), the internal stress field of the composite coal-rock gradually stabilizes after entering the stage of stress-keeping pressure $(\mathrm{AB})$, and the degree of $T_{\text {ave }}$ fluctuation becomes smaller

(2) Linear heating stage: the change trend of $T_{\text {ave }}$ of roof rock, coal, and floor rock is the same as the change trend of the first stage "loading-unloading" (BC) of stress, both of which have a linear rise. The $T_{\text {ave }}$ of the coal body at this stage has the most obvious change, increasing by $1.21^{\circ} \mathrm{C}$. And at $110.49 \mathrm{~s}$, the $T_{\text {ave }}$ of the coal body reaches a local maximum of $21.15^{\circ} \mathrm{C}$, and the time is earlier than floor rock and roof rock

(3) Local decline stage: $T_{\text {ave }}$ of roof rock, coal, and floor rock all show a trend of decreasing first and then becoming stable. Among them, the $T_{\text {ave }}$ of the coal body has decreased by about $0.35^{\circ} \mathrm{C}$, which is in the early stage of the second stage "loading-unloading" (CD) of stress. In this stage, the $T_{\text {ave }}$ of floor rock 

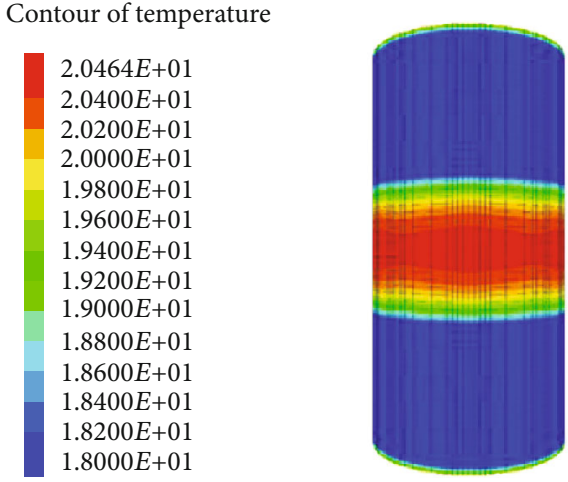

(a) $t=25 \mathrm{~s}$

Contour of temperature

$2.0953 E+01$

$2.0750 E+01$

$2.0500 E+01$

$2.0250 E+01$

$2.0000 E+01$

$1.9750 E+01$

$1.9500 E+01$

$1.9250 E+01$

$1.9000 E+01$

$1.8750 E+01$

$1.8500 E+01$

$1.8250 E+01$

$1.8102 E+01$

(c) $t=90 \mathrm{~s}$

Contour of temperature

$2.2988 E+01$
$2.2750 E+01$
$2.2500 E+01$
$2.2250 E+01$
$2.0000 E+01$
$2.1750 E+01$
$2.1500 E+01$
$2.1250 E+01$
$2.1000 E+01$
$2.0750 E+01$
$2.0500 E+01$
$2.0250 E+01$
$2.0000 E+01$
$1.9750 E+01$
$1.9500 E+01$
$1.9250 E+01$
$1.9000 E+01$

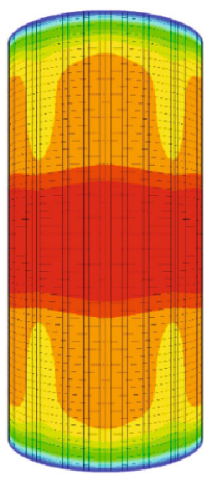

Contour of temperature
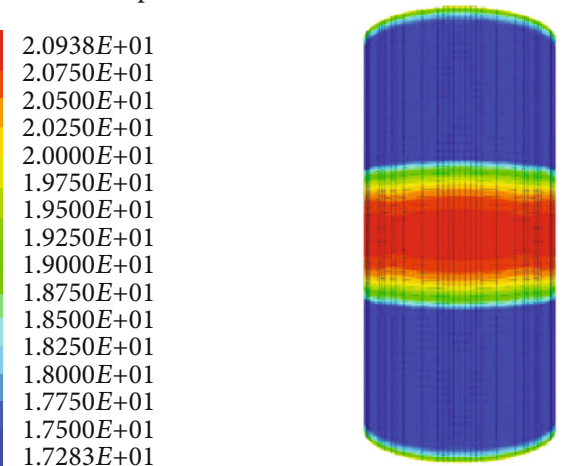

(b) $t=60 \mathrm{~s}$

Contour of temperature
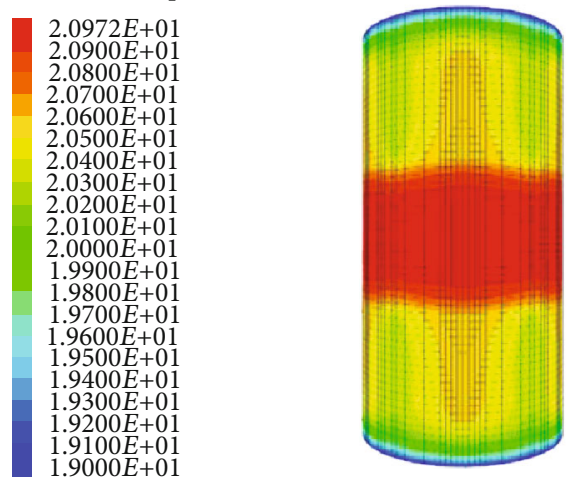

(d) $t=130 \mathrm{~s}$

Contour of temperature

Contour of tem
$2.2822 E+01$

$2.2500 E+01$

$2.2000 E+01$

$2.1500 E+01$

$2.1000 E+0$

$2.0500 E+0$
$2.0000 E+0$

$2.0000 E+0$
$1.9500 E+0$

$1.9500 E+01$
$1.9000 E+01$

$1.9000 E+01$
$1.8500 E+01$

$1.8500 E+01$
$1.8000 E+01$

$1.8000 E+0$
$1.7500 E+0$

$1.7500 E+0$
$1.7000 E+0$

. $6500 E+0$

$1.6500 E+01$
$1.6000 E+01$

$1.6000 E+01$

$.5500 E+0$

$1.5000 E+0$

$1.4500 E+01$
$1.4000 E+01$

$1.4000 E+01$

$1.3500 E+01$
$1.3332 E+01$

(e) $t=146 \mathrm{~s}$

(f) $t=175 \mathrm{~s}$

FIgURE 2: Cloud map of temperature distribution of composite coal-rock. When the simulation time is $25 \mathrm{~s}, 60 \mathrm{~s}, 90 \mathrm{~s}, 130 \mathrm{~s}, 146 \mathrm{~s}$ and $175 \mathrm{~s}$, cloud maps of temperature distribution of composite coal-rock at different times correspond to different stress stages in Figure 1, in which $146 \mathrm{~s}$ is the time point after unloading confining pressure.

and roof rock continued the upward trend of the previous stage, and reached the local maximums of $21.06^{\circ} \mathrm{C}$ and $21.01^{\circ} \mathrm{C}$ at $114.27 \mathrm{~s}$ and $116.78 \mathrm{~s}$ successively. In the gentle trend interval after the decline, the $T_{\text {ave }}$ of the coal body is successively higher than the floor rock and the roof rock

(4) Temperature sudden increase stage: during this stage, $T_{\text {ave }}$ tends to decrease after a sudden increase, and it is in the middle and late stage of the second stage "loading-unloading" (CD) of stress. After the confin- ing pressure is unloaded at $142.5 \mathrm{~s}$, the confining pressure constraint on the composite coal-rock gradually decreased, and the $T_{\text {ave }}$ of the coal body increased suddenly in a short time. At $142.7 \mathrm{~s}$, it first reached the global maximum of $22.53^{\circ} \mathrm{C}$, and then showed a downward trend, decreasing by $0.28^{\circ} \mathrm{C}$. The floor rock and roof rock reached the global maximum of $22.33^{\circ} \mathrm{C}$ and $22.15^{\circ} \mathrm{C}$ successively at $145.23 \mathrm{~s}$ and $146.03 \mathrm{~s}$

(5) Fracture decline stage: after experiencing the combined effect of the previous stress and temperature, 


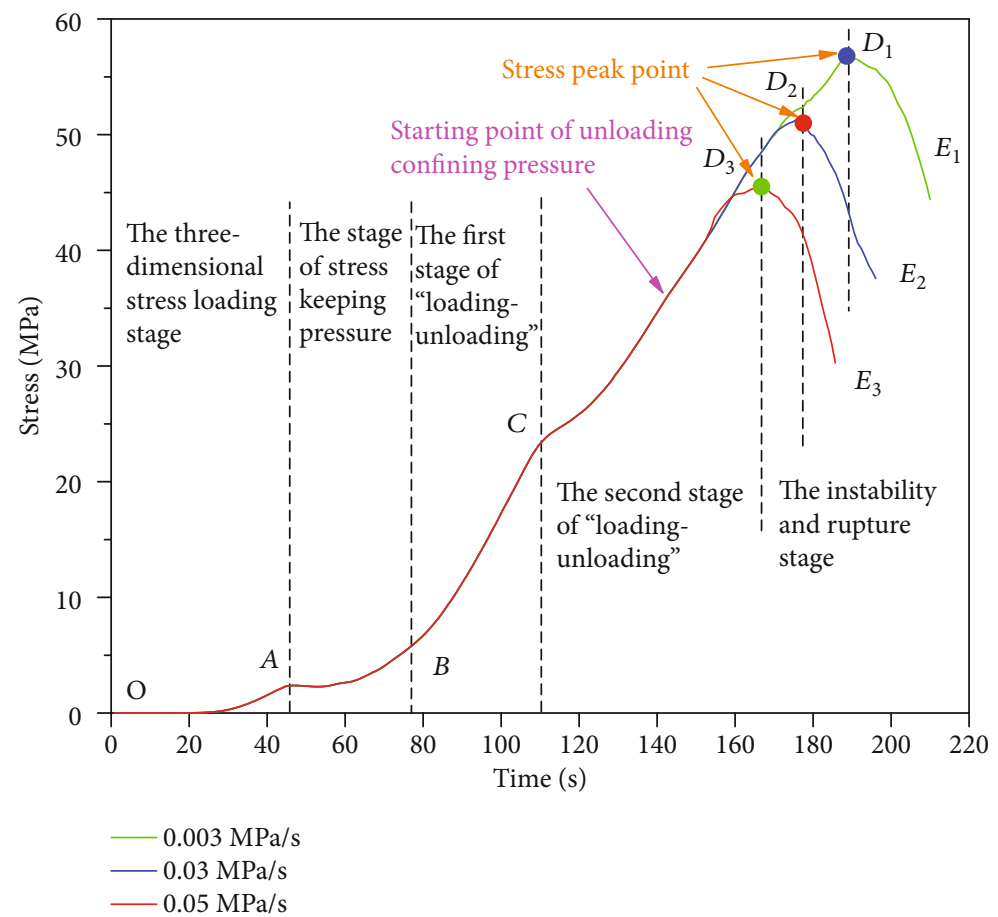

Figure 3: Stress-time curves at different pressure unloading rates. Under the confining pressure of $10 \mathrm{MPa}$ and the unloading rates of $0.003 \mathrm{MPa} / \mathrm{s}, 0.03 \mathrm{MPa} / \mathrm{s}$, and $0.05 \mathrm{MPa} / \mathrm{s}$, the comparison of stress stages in the process of triaxial loading-unloading of composite coalrock was made. Here, $D_{1}, D_{2}$, and $D_{3}$ are the stress peak points under the unloading confining pressure rate of $0.003 \mathrm{MPa} / \mathrm{s}$, $0.03 \mathrm{MPa} / \mathrm{s}$, and $0.05 \mathrm{MPa} / \mathrm{s}$, respectively.

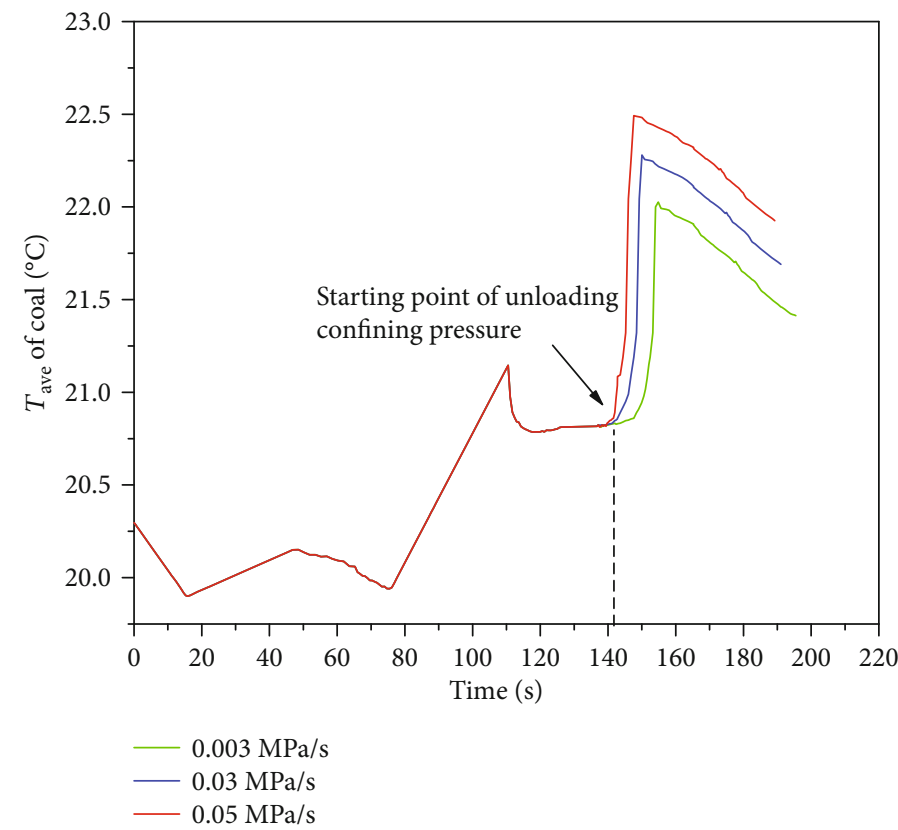

FiguRE 4: $T_{\text {ave }}-t$ curves of thermal infrared radiation at different confining pressure unloading rates. Under the confining pressure of $10 \mathrm{MPa}$ and the unloading rates of $0.003 \mathrm{MPa} / \mathrm{s}, 0.03 \mathrm{MPa} / \mathrm{s}$, and $0.05 \mathrm{MPa} / \mathrm{s}$, the temperature changes during the triaxial loading-unloading process of composite coal were compared, and the confining pressure unloading time was $142.5 \mathrm{~s}$. 


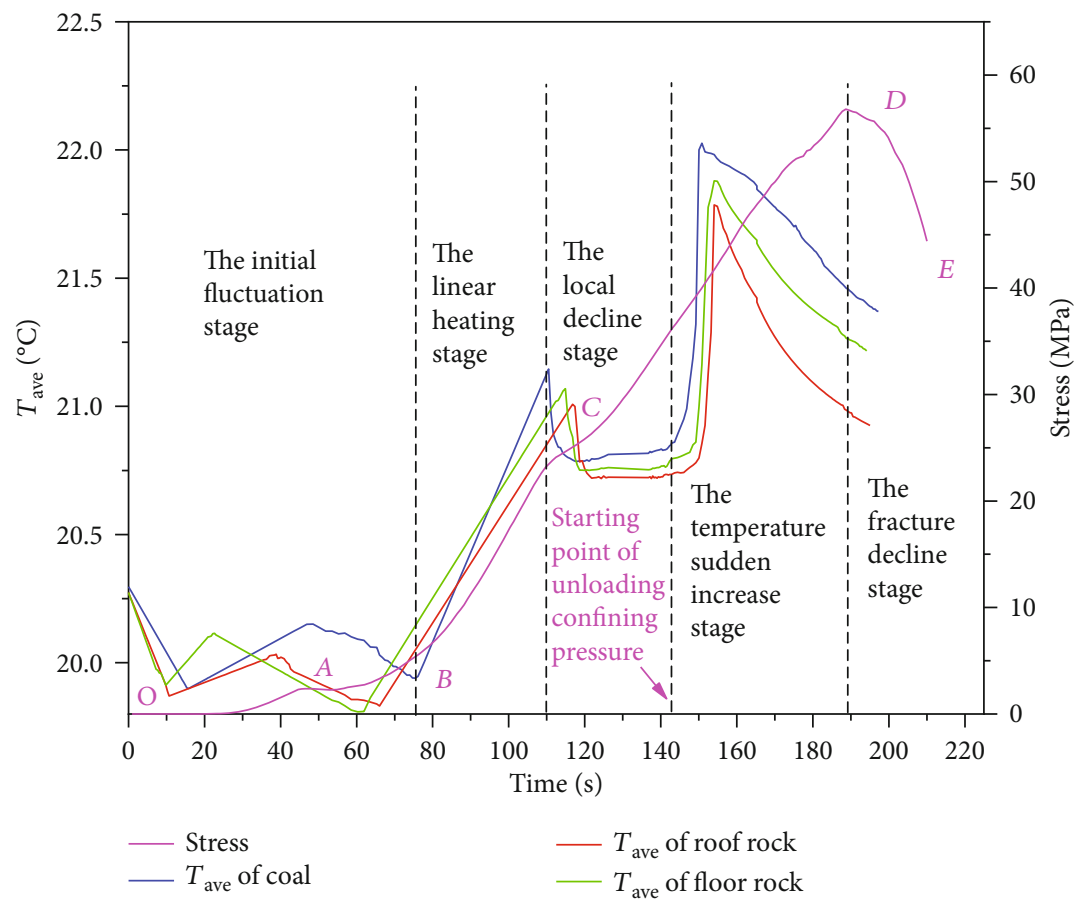

(a)

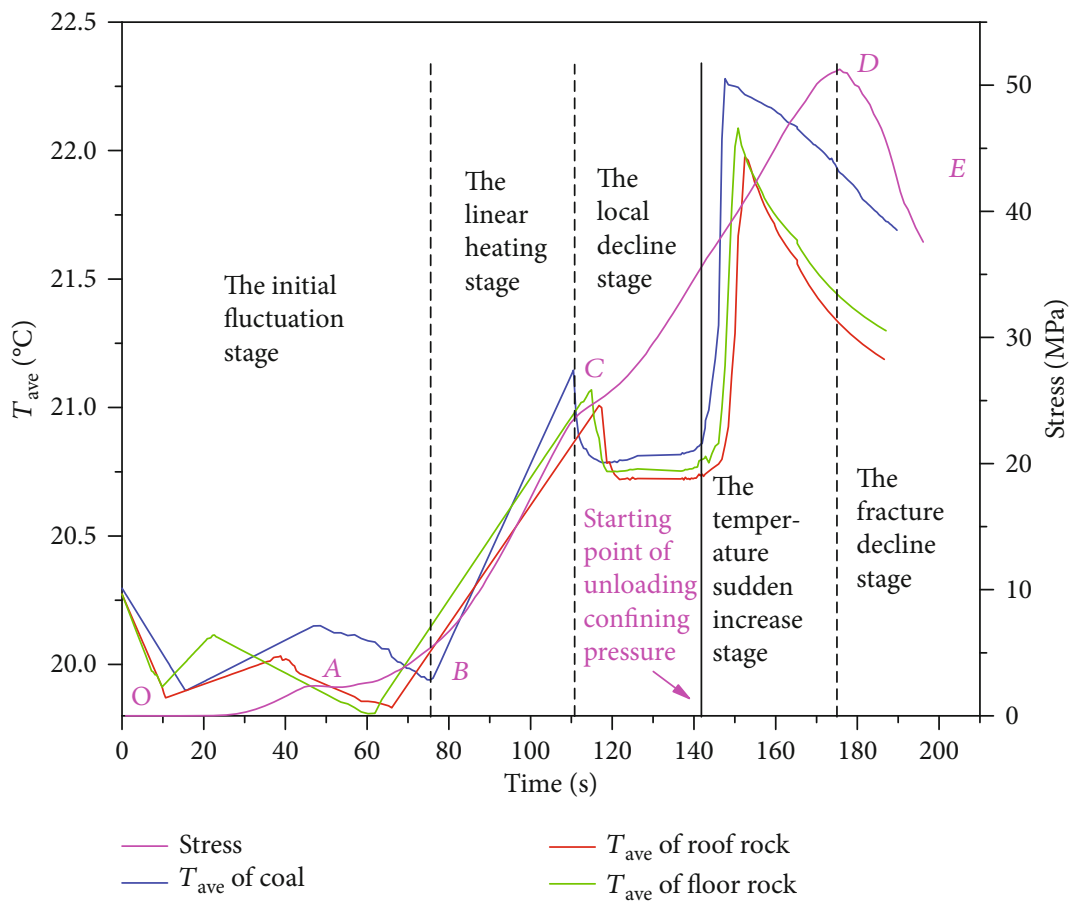

(b)

Figure 5: Continued. 


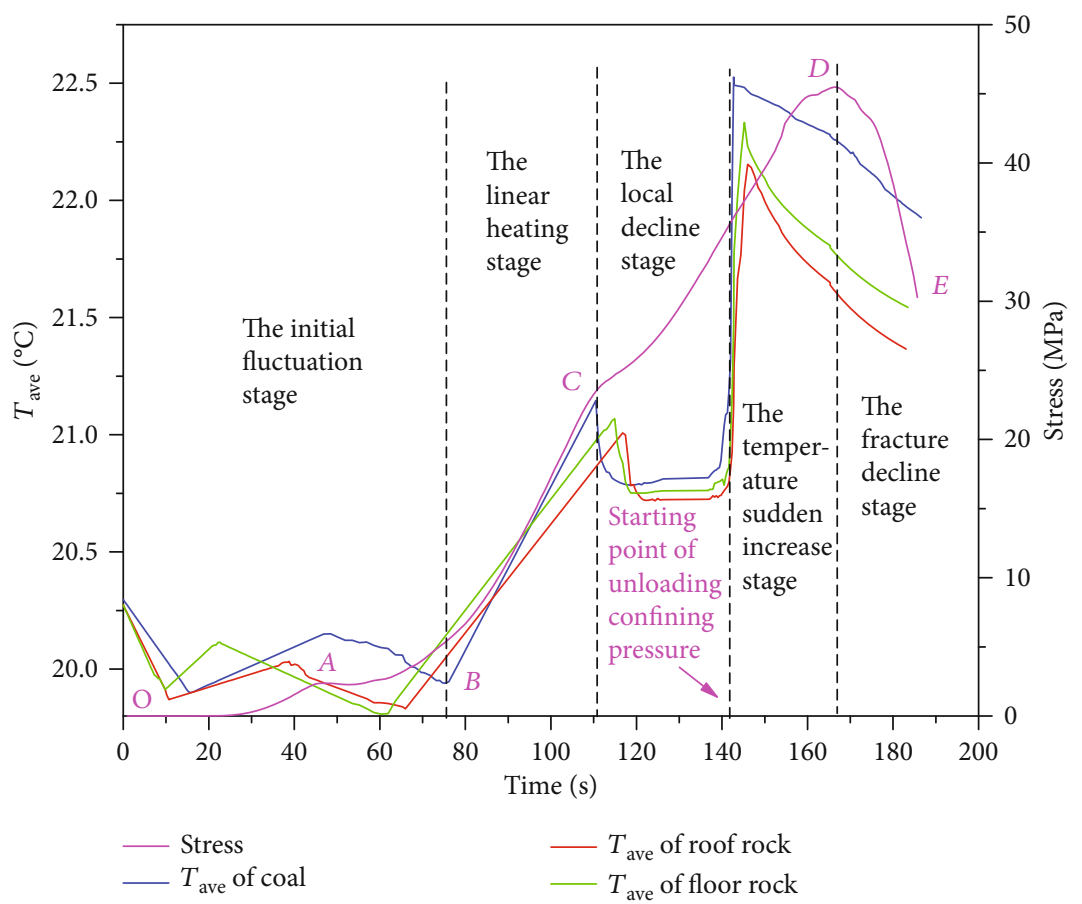

(c)

FIGURE 5: $T_{\text {ave }}-\sigma$ - $t$ curve of composite coal-rock. Among them, (a), (b), and (c) are the $T_{\text {ave }}-\sigma-t$ curves of composite coal-rock under the conditions of $0.003 \mathrm{MPa} / \mathrm{s}, 0.03 \mathrm{MPa} / \mathrm{s}$, and $0.05 \mathrm{MPa} / \mathrm{s}$ confining pressure unloading rate, respectively.

the composite coal-rock has reached the bearing limit at $167.6 \mathrm{~s}$ and it is unstable and damaged at point $D$. At this stage, the $T_{\text {ave }}$ continues to decline as in the previous stage, and it is in the instability and rupture stage (DE) of stress

3.1.3. The Correlation between Thermal Infrared Radiation Temperature and Stress. The surface average infrared radiation temperature and stress of the composite coal body, roof rock, and floor rock are fitted to obtain the linear fitting relationship expression between the average thermal infrared radiation temperature and stress:

$$
T_{\text {ave }}=K \sigma+T_{1} \text {, }
$$

where $T_{\text {ave }}$ is the surface average thermal infrared radiation temperature of each component of the composite coal-rock at any time $\left({ }^{\circ} \mathrm{C}\right), K$ is the slope of the fitting curve, $\sigma$ is the stress $(\mathrm{MPa}), T_{1}$ is the starting temperature of the linear heating stage $\left({ }^{\circ} \mathrm{C}\right)$.

Figure 6 shows the fitting curves of the $T_{\text {ave }}$ and stress on the surface of the composite coal-rock with different components under different unloading rates. The expression of the linear relationship between the $T_{\text {ave }}$ and stress on the coal surface in Figure 6(c) is as follows:

$$
T_{\text {ave }}=0.06204 \sigma+19.63599 \text {, }
$$

where the linear correlation coefficient obtained by fitting is 0.924 .
A linear fitting is performed on the $T_{\text {ave }}$ and the axial stress of the roof rock surface, and the linear relationship between the $T_{\text {ave }}$ and the stress is obtained as follows:

$$
T_{\text {ave }}=0.04479 \sigma+19.77547
$$

where the linear correlation coefficient obtained by fitting is 0.93553 .

A linear fitting is performed on the $T_{\text {ave }}$ and the axial stress of the floor rock surface, and the linear relationship between the $T_{\text {ave }}$ and the stress is obtained as follows:

$$
T_{\text {ave }}=0.04776 \sigma+19.80128,
$$

where the linear correlation coefficient obtained by fitting is 0.92295 .

According to the fitting parameters in Table 2 (unloading confining pressure at a rate of $0.003 \mathrm{MPa} / \mathrm{s}$ and $0.03 \mathrm{MPa} / \mathrm{s}$ ), the linear correlation coefficients of the $T_{\text {ave }}$ and stress after fitting are all greater than 0.89 . So, there is a strong linear correlation between the average thermal infrared radiation temperature and the stress on the surface of composite coal-rock under different working conditions.

3.1.4. Experimental Verification. Figure 7 is a schematic diagram of the triaxial test equipment and field testing. The test system consists of a triaxial test machine, dynamic data acquisition, power control cabinet, and computer. In order to ensure that temperature data can be collected in a closed environment, an observation window is set at the confining cylinder of the test machine. This article uses the TAW- 


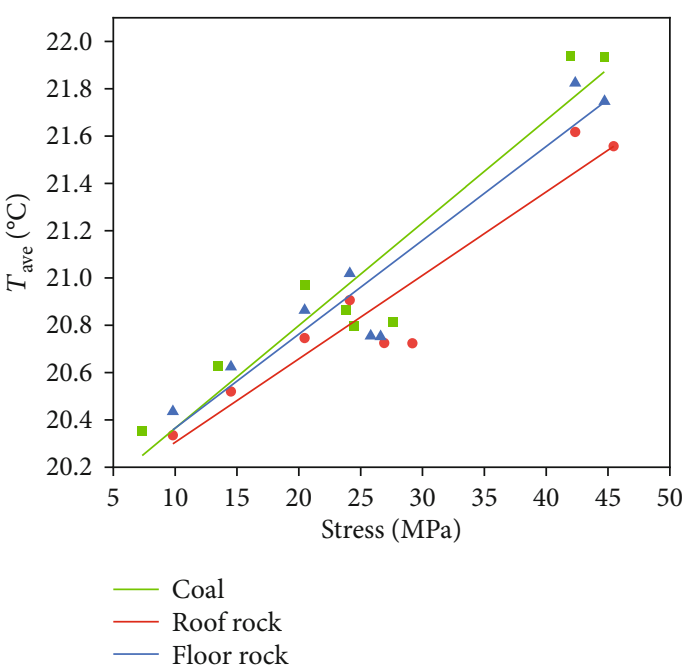

(a)

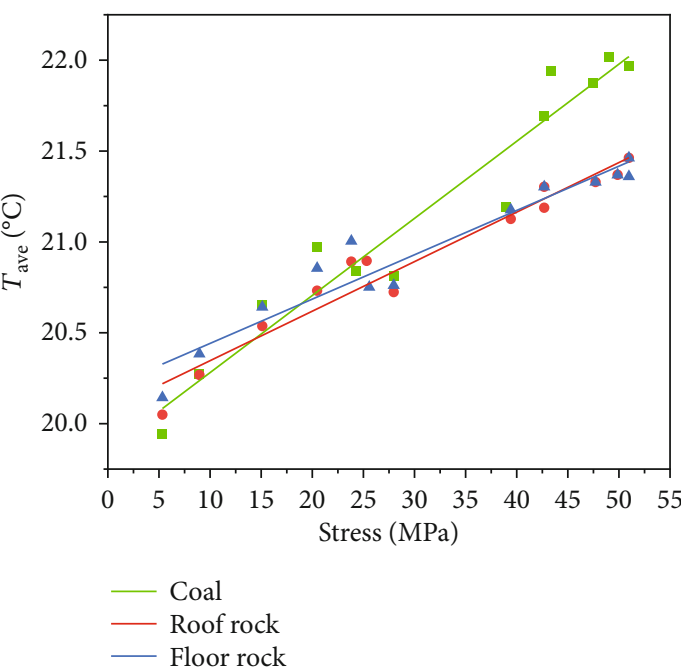

(b)

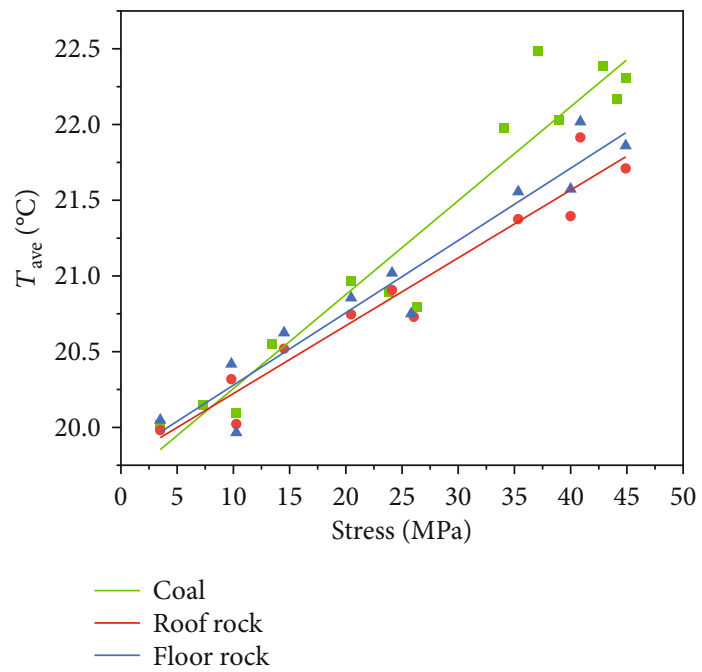

(c)

FIGURE 6: Linear fitting of mean thermal infrared radiation temperature and stress. Here, (a), (b), and (c) are linear fitting results of composite coal-rock under confining pressure unloading rates of $0.003 \mathrm{MPa} / \mathrm{s}, 0.03 \mathrm{MPa} / \mathrm{s}$, and $0.05 \mathrm{MPa} / \mathrm{s}$, respectively.

TABLE 2: Linear fitting parameters between $T_{\text {ave }}$ and stress at different pressure unloading rates.

\begin{tabular}{lcccc}
\hline $\begin{array}{l}\text { Discharge } \\
\text { confining pressure } \\
\text { rate }(\mathrm{MPa} / \mathrm{s})\end{array}$ & Sample & $\begin{array}{c}\text { Correlation } \\
\text { coefficient }\end{array}$ & Slope & Intercept \\
\hline \multirow{2}{*}{0.003} & Coal & 0.90224 & 0.04342 & 19.93063 \\
& Roof rock & 0.90156 & 0.03529 & 19.95223 \\
& Floor rock & 0.89696 & 0.03969 & 19.96863 \\
\hline \multirow{3}{*}{0.03} & Coal & 0.93408 & 0.04243 & 19.85666 \\
& Roof rock & 0.9459 & 0.02726 & 20.07382 \\
& Floor rock & 0.9212 & 0.02439 & 20.19758 \\
\hline
\end{tabular}

2000 microcomputer-controlled high-temperature rock triaxial testing machine for testing. This equipment can collect, store, process, and display test data and test curves in real time during the test. The average infrared radiation tem- perature of the sample is collected by the ThermoView ${ }^{\mathrm{TM}} \mathrm{Pi} 20$ infrared thermal imager; that is, the average infrared radiation temperature corresponds to all the pixels on the thermal infrared image of the sample surface at a certain moment. The spectral response of the infrared thermal imager is $8 \sim 14 \mu \mathrm{m}$, and the sensitivity is $0.03^{\circ} \mathrm{C}$.

The coal and rock samples were selected from the coal seams with strong impact at Feng Shuigou Coal Mine in Pingzhuang, Inner Mongolia. In the actual coal mine, the coal seam is mostly sandwiched in the rock layer, which basically presents the three-layer structure of "rock-coal-rock." According to this characteristic, the composite coal-rock samples used in the test are processed [45]. Through field exploration and comparison, materials were taken from the field, and fresh coal samples with both roof and floor siltstone were drilled. In the laboratory, the roof rock, coal sample, and floor rock were cut and bonded at a ratio of $1: 1: 1$ into 20 cylindrical samples with a diameter of $50 \mathrm{~mm}$ and a height 


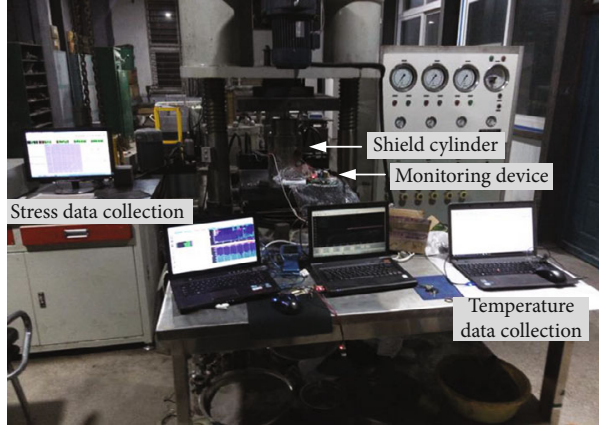

(a) Schematic diagram of field test

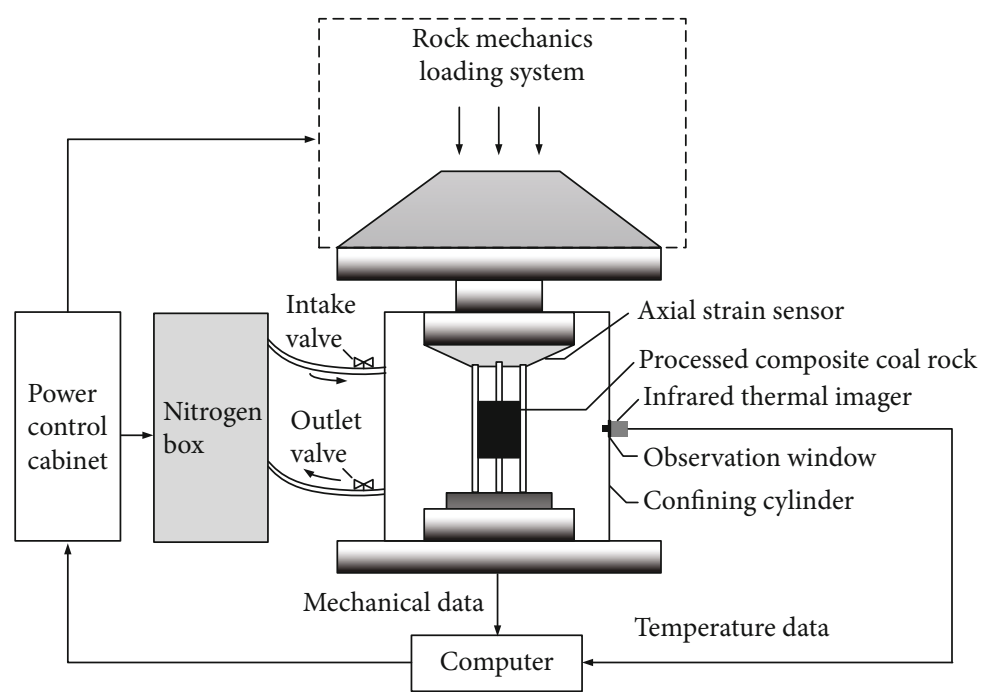

(b) Schematic diagram of test equipment

Figure 7: Schematic diagram of test equipment and field test. Figure 7(a) is the schematic diagram of the field test, and Figure 7(b) is the schematic diagram of the test equipment. The test equipment is mainly composed of a triaxial test machine, a power control cabinet, a nitrogen box, an infrared thermal imager, and a computer. Power is supplied by the power control cabinet during the experiment. The inlet valve and outlet valve of the nitrogen tank are responsible for controlling the pressurization of the processed composite coal-rock. An observation window is set on the shielding cylinder of the three-axis testing machine, and an infrared thermal imager is placed here to collect the $T_{\text {ave }}$ data of the samples. The mechanics and temperature data are uniformly transmitted to the computer for display and storage.

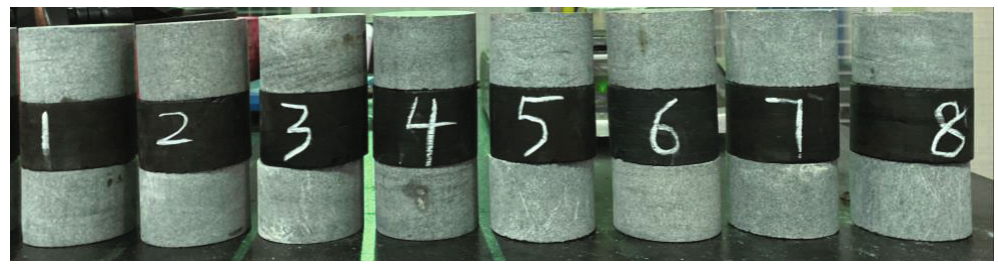

FIgURE 8: Partial composite coal-rock specimen.

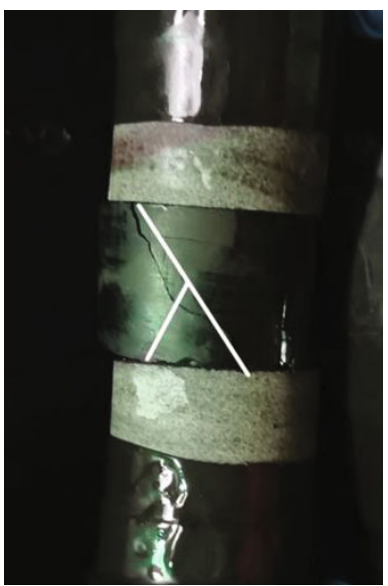

(a)

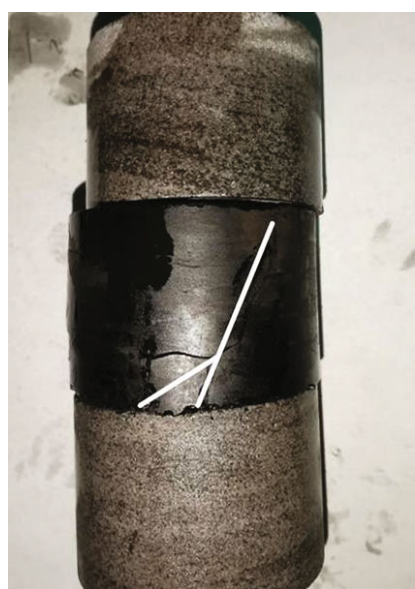

(b)

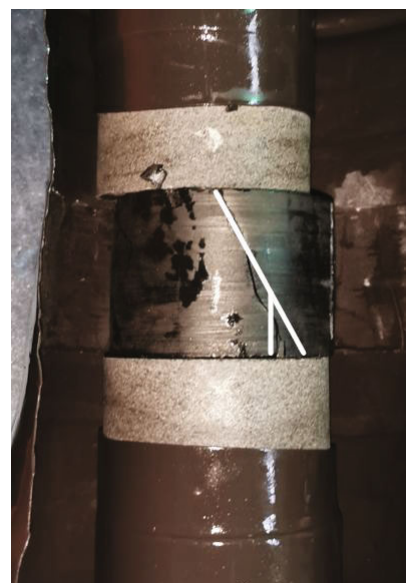

(c)

Figure 9: Experimental results of samples $1^{\#}, 6^{\#}$, and $11^{\#}$. Among them, (a) is the $T_{\text {ave }}-\sigma$ - $t$ experimental curve of sample $1^{\#}$ when the unloading confining pressure rate is $0.003 \mathrm{MPa} / \mathrm{s} ;(\mathrm{b})$ is the $T_{\text {ave }}-\sigma-t$ experimental curve of sample $6^{\#}$ when the unloading confining pressure rate is $0.03 \mathrm{MPa} / \mathrm{s}$; (c) is the $T_{\text {ave }}-\sigma-t$ experimental curve of sample $11^{\#}$ when the unloading confining pressure rate is $0.05 \mathrm{MPa} / \mathrm{s}$.

of $100 \mathrm{~mm}$. Five samples are reserved for a composite coalrock pretest, and the remaining samples are subjected to triaxial loading-unloading tests at different unloading confining pressure rates, numbered $1^{\#}, 2^{\#}, 3^{\#}, 4^{\#}, 5^{\#}, 6^{\#}, 7^{\#}, 8^{\#}, 9^{\#}, 10^{\#}$, $11^{\#}, 12^{\#}, 13^{\#}, 14^{\#}$, and $15^{\#}$. Some composite coal-rock samples are shown in Figure 8. 

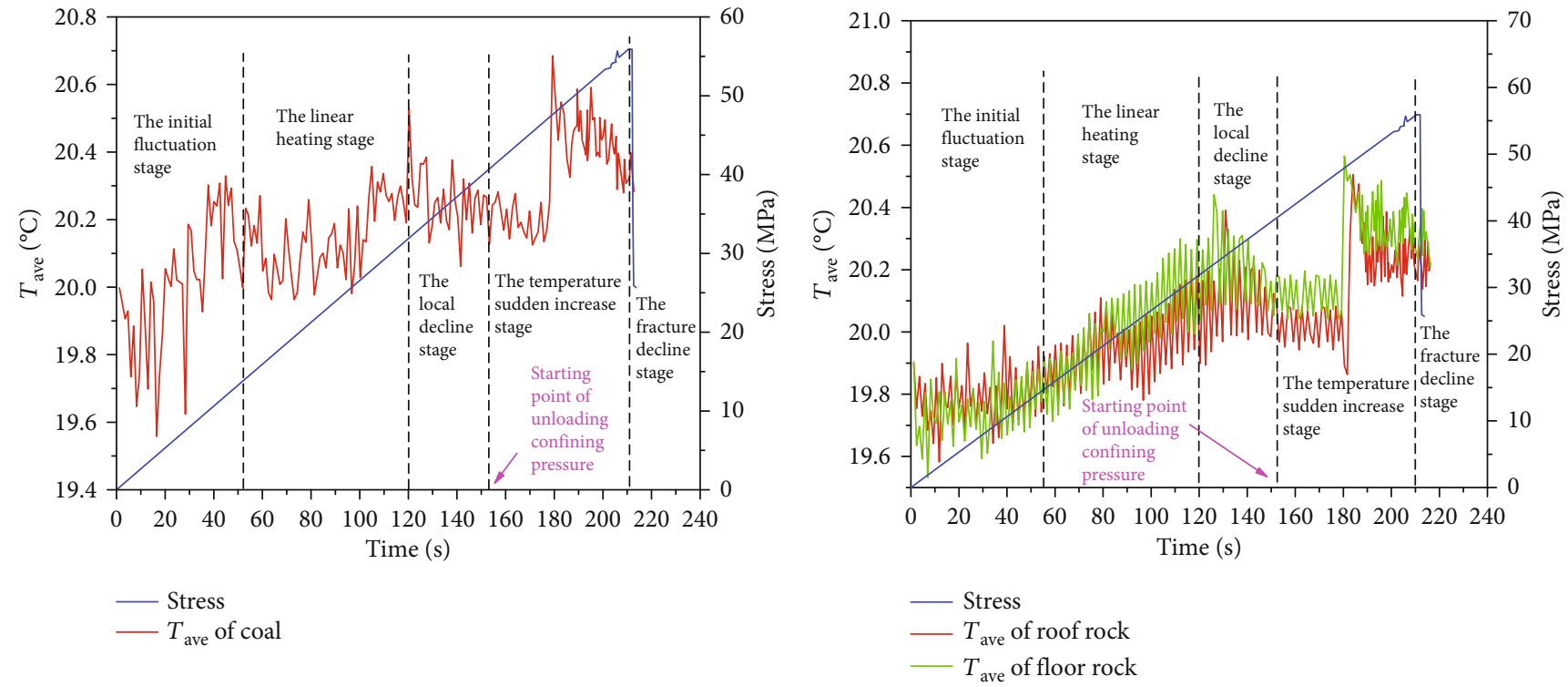

(a) $T_{\text {ave }}-\sigma$ - $t$ experimental curves of different components of sample $1^{\#}$
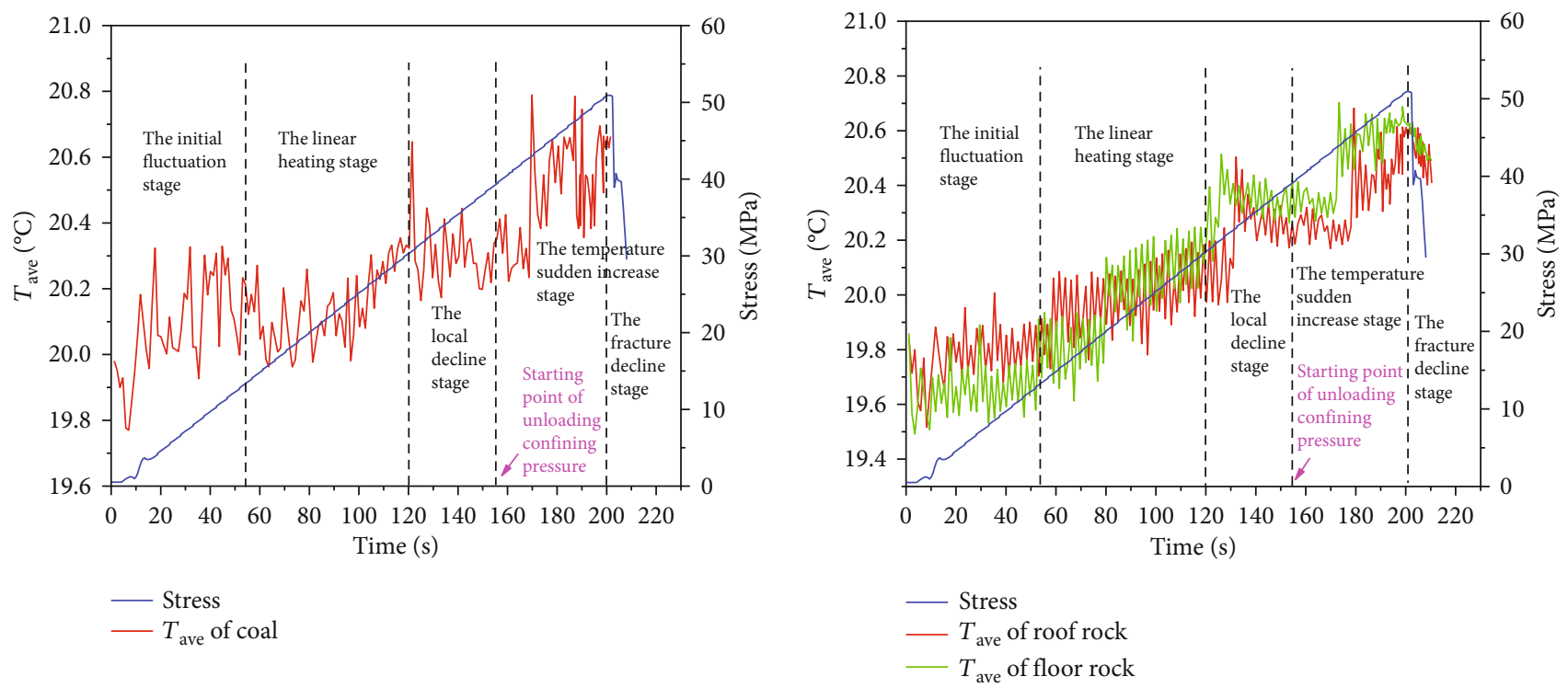

(b) $T_{\text {ave }}-\sigma$ - $t$ experimental curves of different components of sample $6^{\#}$

Figure 10: Continued. 

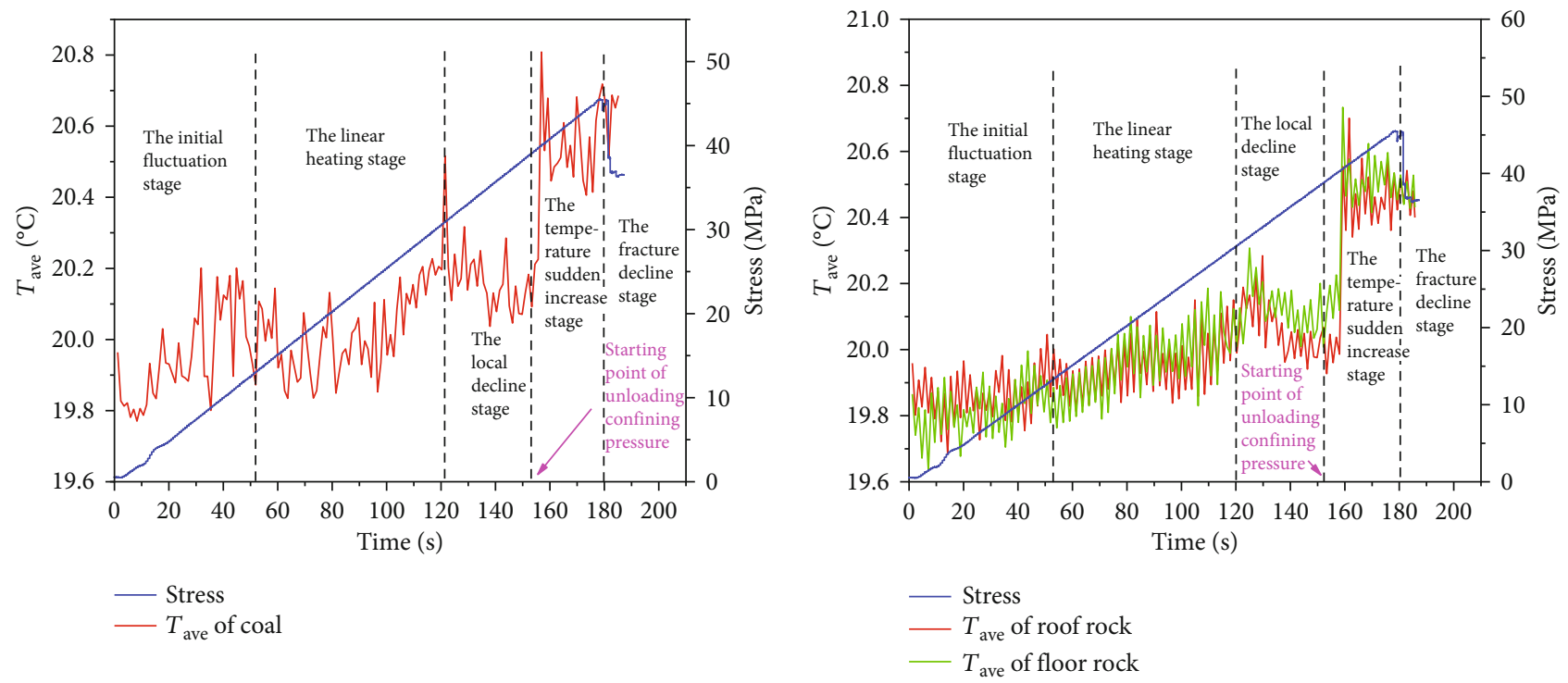

(c) $T_{\text {ave }}-\sigma-t$ experimental curves of different components of sample $11^{\#}$

Figure 10: $T_{\text {ave }}-\sigma-t$ experimental curves of different components of composite coal-rock. Among them, (a), (b), and (c) are the $T_{\text {ave }}-\sigma-t$ experimental curves of the samples $1^{\#}, 6^{\#}$, and $11^{\#}$ at the unloading confining pressure rate of $0.003 \mathrm{MPa} / \mathrm{s}, 0.03 \mathrm{MPa} / \mathrm{s}$, and $0.05 \mathrm{MPa} / \mathrm{s}$, respectively.

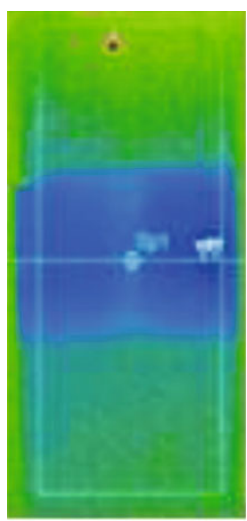

(a) $t=20 s$

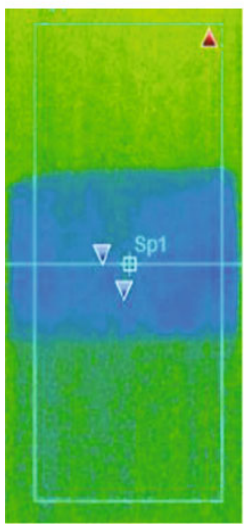

(d) $t=130 s$

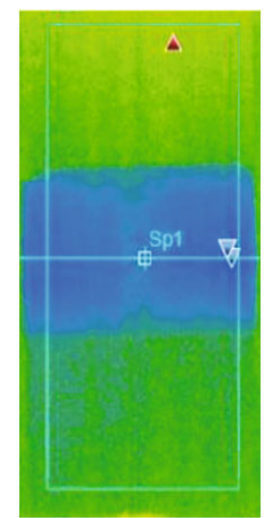

(b) $\mathrm{t}=40 \mathrm{~s}$

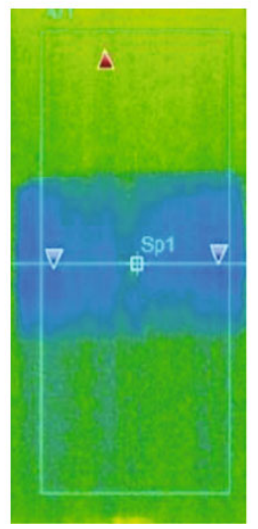

(e) $\mathrm{t}=160 \mathrm{~s}$
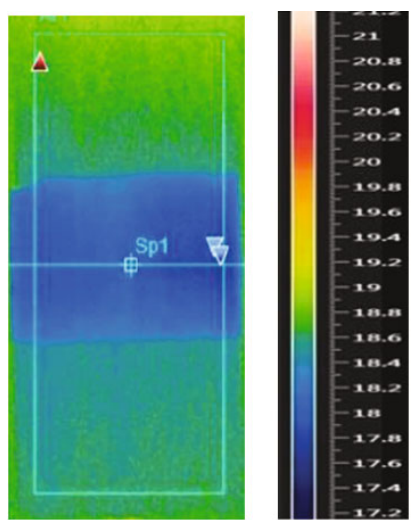

(c) $\mathrm{t}=90 \mathrm{~s}$
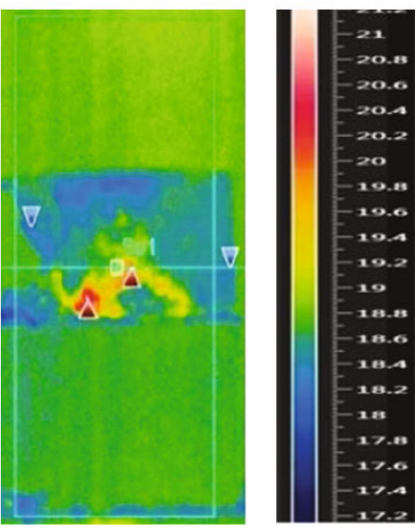

(f) $\mathrm{t}=180 \mathrm{~s}$

Figure 11: Thermal imaging of the sample $11^{\#}$. Here, (a), (b), (c), (d), (e), and (f) are the thermal infrared imaging images of the sample $11^{\#}$ at the rate of $0.05 \mathrm{MPa} / \mathrm{s}$ when the experimental times are $20 \mathrm{~s}, 40 \mathrm{~s}, 90 \mathrm{~s}, 130 \mathrm{~s}, 160 \mathrm{~s}$, and $180 \mathrm{~s}$, respectively. Among them, $160 \mathrm{~s}$ is the thermal infrared image after the confining pressure has just been unloaded. 
TABLE 3: Comparison of $T_{\text {ave }}$ and peak stress parameters of coal body under different pressure relief rates.

\begin{tabular}{|c|c|c|c|c|c|}
\hline \multirow{2}{*}{ Confining pressure unloading rate $(\mathrm{MPa} / \mathrm{s})$} & \multirow{2}{*}{ Sample } & \multicolumn{2}{|c|}{$T_{\text {ave }}$} & \multicolumn{2}{|c|}{ Stress } \\
\hline & & Peak time (s) & Peak size $\left({ }^{\circ} \mathrm{C}\right)$ & Peak time $(s)$ & Peak size $(\mathrm{MPa})$ \\
\hline \multirow{5}{*}{0.003} & $1^{\#}$ & 179.3 & 20.69 & 210.7 & 55.92 \\
\hline & $2^{\#}$ & 180.7 & 20.52 & 213.9 & 57.67 \\
\hline & $3^{\#}$ & 182.5 & 20.45 & 212.5 & 56.81 \\
\hline & $4^{\#}$ & 179.1 & 20.66 & 210.3 & 55.70 \\
\hline & $5^{\#}$ & 180.3 & 20.71 & 213.4 & 57.49 \\
\hline \multirow{5}{*}{0.03} & $6^{\#}$ & 169.8 & 20.79 & 200.9 & 50.91 \\
\hline & $7^{\#}$ & 170.4 & 20.73 & 199.8 & 50.69 \\
\hline & $8^{\#}$ & 169.7 & 20.76 & 198.5 & 49.83 \\
\hline & $9^{\#}$ & 168.6 & 20.75 & 201.3 & 49.74 \\
\hline & $10^{\#}$ & 168.4 & 20.73 & 201.1 & 49.69 \\
\hline \multirow{5}{*}{0.05} & $11^{\#}$ & 156.9 & 20.81 & 180.7 & 45.46 \\
\hline & $12^{\#}$ & 157.1 & 20.92 & 183.4 & 46.79 \\
\hline & $13^{\#}$ & 156.3 & 20.87 & 181.9 & 45.51 \\
\hline & $14^{\#}$ & 155.8 & 20.94 & 177.1 & 45.39 \\
\hline & $15^{\#}$ & 156.8 & 20.73 & 180.2 & 45.37 \\
\hline
\end{tabular}

The symbol "\#” constitutes the label of the "coal-rock-coal" sample, which is explained in Section 3.1.4.

The experiment steps are as follows:

(1) At room temperature, seal the composite coal-rock sample with a thermoplastic tube and put it in a confining cylinder

(2) Connect the thermal imaging camera to the computer, aim the front of the thermal imaging camera at the observation window to the observation surface of the sample, turn on the power, open the software to connect the thermal imaging camera, and check the thermal imaging camera status

(3) Open the nitrogen valve of the testing machine to inject nitrogen, and close the gas valve when it is full

(4) Apply three-dimensional stress to the sample to a predetermined confining pressure value of $10 \mathrm{MPa}$

(5) Pretest: keep the confining pressure unchanged, load the sample under axial compression at a displacement rate of $0.05 \mathrm{~mm} / \mathrm{min}$. Record the peak stress intensity, and obtain the average value of the peak stress intensity of the five samples

(6) Triaxial loading-unloading test: divide samples $1^{\#} \sim 15^{\#}$ into three groups equally, repeat steps (1), (2), (3), and (4), set the same triaxial loading conditions as the pretest. When the stress reaches about $80 \%$ of the average value of the peak strength, the confining pressure will be relieved. And the unloading rate is set to $0.003 \mathrm{MPa} / \mathrm{s}$ (samples $1^{\#}, 2^{\#}, 3^{\#}, 4^{\#}$, and $5^{\#}$ ), $0.03 \mathrm{MPa} / \mathrm{s}$ (samples $6^{\#}, 7^{\#}, 8^{\#}, 9^{\#}$, and $10^{\#}$ ), and $0.05 \mathrm{MPa} / \mathrm{s}$ (samples $11^{\#}, 12^{\#}, 13^{\#}, 14^{\#}$, and $15^{\#}$ ), keep the axial pressure to continue loading during the unloading process. When the axial stress exceeds the peak stress and the sample is damaged, immediately stop the confining pressure unloading operation. Keep the confining pressure unchanged, and continue to apply the axial stress until the stress curve no longer changes with the change of strain, and the test ends

In the pretest, the average value of unloading confining pressure is $39 \mathrm{MPa}$. Since the samples are randomly grouped, the first samples, namely, sample $1^{\#}, 6^{\#}$, and $11^{\#}$, are selected for comparison in the three groups of different confining pressure unloading rate tests. Figure 9 shows the test results of samples $1^{\#}, 6^{\#}$, and $11^{\#}$. It can be seen from Figure 9 that the cracks of the sample mainly exist in the coal seam and show an inverted "Y-shaped" splitting fracture. And the rock mass has microcracks, but these are not obvious. This is due to the relatively high strength of the sample, the more prominent end effect, and the end is in a three-way stress state due to friction restraint.

The $T_{\text {ave }}-\sigma$ - $t$ curves of samples $1^{\#}, 6^{\#}$, and $11^{\#}$ are shown in Figure 10, and the trends of the three curves are the same. Combining Figures 9 and 10, the greater the confining pressure relief rate, the greater the $T_{\text {ave }}$ peak, the more severe the mechanical changes caused by heat, the more obvious the thermal-mechanical coupling effect, and the shorter the sample rupture time. Therefore, the cracks in the sample are too late to fully expand, and the more the damage is concentrated on a certain macroscopic fracture surface, the lower the overall degree of fracture. During the loading-unloading process, the formation, expansion and fusion of microcracks within the coal sample occur. As the stress increases, the $T_{\text {ave }}$ shows an upward trend, and local peak value and global maximum value appear. Since the strength of the roof and floor rocks is much greater than the coal body, the coal body was unstable and fractured at the end of the test. Although cracks propagated inside the rock mass, the rock mass itself did not break obviously. The $T_{\text {ave }}$ of the roof and floor rocks showed an upward trend. After the confining pressure was relieved, the 
TABLE 4: Fitting equations at different pressure release rates.

\begin{tabular}{|c|c|c|c|c|}
\hline Confining pressure unloading rate $(\mathrm{MPa} / \mathrm{s})$ & Number & Sample & Fitting equation & Correlation coefficient \\
\hline & & Coal & $T_{\text {ave }}=0.00605 \sigma+19.87015$ & 0.93496 \\
\hline & $1^{\#}$ & Roof rock & $T_{\mathrm{ave}}=0.00546 \sigma+19.8574$ & 0.90399 \\
\hline & & Floor rock & $T_{\text {ave }}=0.00539 \sigma+19.84124$ & 0.94312 \\
\hline & & Coal & $T_{\mathrm{ave}}=0.0053 \sigma+19.86009$ & 0.92674 \\
\hline & $2^{\#}$ & Roof rock & $T_{\text {ave }}=0.00684 \sigma+19.84865$ & 0.91652 \\
\hline & & Floor rock & $T_{\text {ave }}=0.007169 \sigma+19.83063$ & 0.93705 \\
\hline & & Coal & $T_{\text {ave }}=0.00746 \sigma+19.83876$ & 0.94878 \\
\hline \multirow[t]{15}{*}{0.003} & $3^{\#}$ & Roof rock & $T_{\text {ave }}=0.006098 \sigma+19.87914$ & 0.93514 \\
\hline & & Floor rock & $T_{\mathrm{ave}}=0.006134 \sigma+19.88518$ & 0.94677 \\
\hline & & Coal & $T_{\text {ave }}=0.0061 \sigma+19.89534$ & 0.92781 \\
\hline & $4^{\#}$ & Roof rock & $T_{\text {ave }}=0.00587 \sigma+19.86495$ & 0.92695 \\
\hline & & Floor rock & $T_{\text {ave }}=0.00693 \sigma+19.84713$ & 0.91746 \\
\hline & & Coal & $T_{\mathrm{ave}}=0.0053 \sigma+19.86009$ & 0.91462 \\
\hline & $5^{\#}$ & Roof rock & $T_{\text {ave }}=0.00684 \sigma+19.84865$ & 0.90857 \\
\hline & & Floor rock & $T_{\mathrm{ave}}=0.007169 \sigma+19.83063$ & 0.91039 \\
\hline & & Coal & $T_{\text {ave }}=0.00664 \sigma+19.89496$ & 0.96174 \\
\hline & $6^{\#}$ & Roof rock & $T_{\mathrm{ave}}=0.00956 \sigma+19.77254$ & 0.96367 \\
\hline & & Floor rock & $T_{\mathrm{ave}}=0.0091 \sigma+19.79735$ & 0.95806 \\
\hline & & Coal & $T_{\mathrm{ave}}=0.00796 \sigma+19.89691$ & 0.95763 \\
\hline & $7^{\#}$ & Roof rock & $T_{\mathrm{ave}}=0.008565 \sigma+19.76841$ & 0.91875 \\
\hline & & Floor rock & $T_{\text {ave }}=0.009197 \sigma+19.84372$ & 0.93548 \\
\hline & & Coal & $T_{\text {ave }}=0.008097 \sigma+19.90263$ & 0.94097 \\
\hline \multirow[t]{14}{*}{0.03} & $8^{\#}$ & Roof rock & $T_{\text {ave }}=0.007156 \sigma+19.77987$ & 0.95875 \\
\hline & & Floor rock & $T_{\text {ave }}=0.00785 \sigma+19.80753$ & 0.96864 \\
\hline & & Coal & $T_{\mathrm{ave}}=0.00608 \sigma+19.90534$ & 0.93254 \\
\hline & $9^{\#}$ & Roof rock & $T_{\mathrm{ave}}=0.00896 \sigma+19.72962$ & 0.92175 \\
\hline & & Floor rock & $T_{\text {ave }}=0.00873 \sigma+19.78641$ & 0.91867 \\
\hline & & Coal & $T_{\mathrm{ave}}=0.00749 \sigma+19.74125$ & 0.92671 \\
\hline & $10^{\#}$ & Roof rock & $T_{\text {ave }}=0.00928 \sigma+19.70962$ & 0.91538 \\
\hline & & Floor rock & $T_{\mathrm{ave}}=0.009143 \sigma+19.6831$ & 0.91274 \\
\hline & & Coal & $T_{\mathrm{ave}}=0.00829 \sigma+19.83793$ & 0.93825 \\
\hline & $11^{\#}$ & Roof rock & $T_{\text {ave }}=0.00676 \sigma+19.87256$ & 0.9199 \\
\hline & & Floor rock & $T_{\mathrm{ave}}=0.00731 \sigma+19.86935$ & 0.95169 \\
\hline & & Coal & $T_{\text {ave }}=0.008754 \sigma+19.83763$ & 0.94761 \\
\hline & $12^{\#}$ & Roof rock & $T_{\text {ave }}=0.002570 \sigma+19.87754$ & 0.92867 \\
\hline & & Floor rock & $T_{\mathrm{ave}}=0.00571 \sigma 19.83333$ & 0.94652 \\
\hline \multirow[t]{7}{*}{0.05} & & Coal & $T_{\text {ave }}=0.009753 \sigma+19.83659$ & 0.95173 \\
\hline & $13^{\#}$ & Roof rock & $T_{\mathrm{ave}}=0.004627 \sigma+19.87074$ & 0.93635 \\
\hline & & Floor rock & $T_{\mathrm{ave}}=0.00478 \sigma+19.87988$ & 0.94174 \\
\hline & & Coal & $T_{\mathrm{ave}}=0.0086 \sigma+19.80651$ & 0.93045 \\
\hline & $14^{\#}$ & Roof rock & $T_{\mathrm{ave}}=0.00537 \sigma+19.90571$ & 0.92435 \\
\hline & & Floor rock & $T_{\mathrm{ave}}=0.00548 \sigma+19.88145$ & 0.92037 \\
\hline & $15^{*}$ & Coal & $T_{\text {ave }}=0.008741 \sigma+19.80253$ & 0.92754 \\
\hline
\end{tabular}


TABLE 4: Continued.

\begin{tabular}{lcccc}
\hline Confining pressure unloading rate $(\mathrm{MPa} / \mathrm{s})$ & Number & Sample & Fitting equation & Correlation coefficient \\
\hline & Roof rock & $T_{\text {ave }}=0.00487 \sigma+19.88475$ & 0.91863 \\
& Floor rock & $T_{\text {ave }}=0.00496 \sigma+19.87033$ & 0.91384 \\
\hline
\end{tabular}

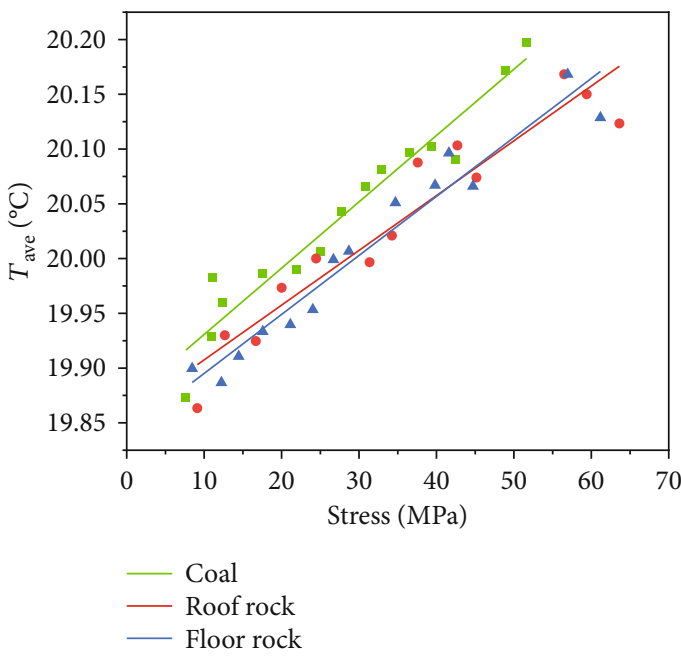

(a) Sample $1^{\#}$

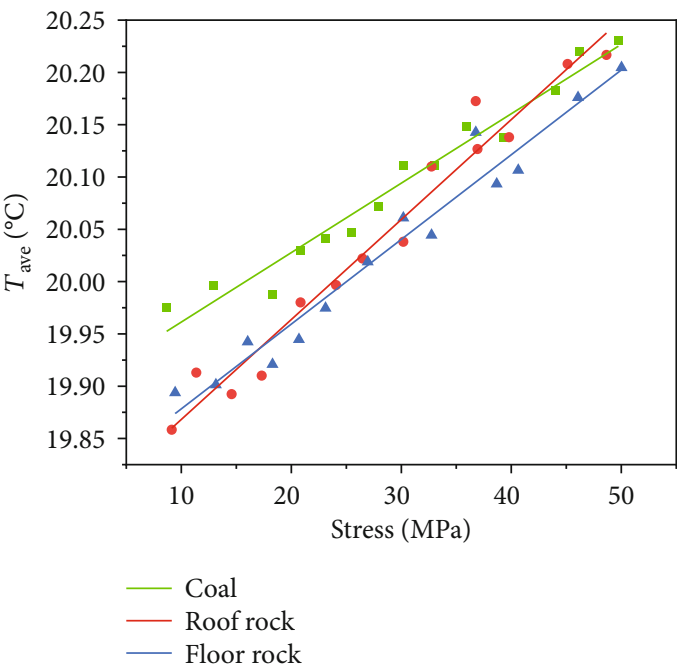

(b) Sample 6

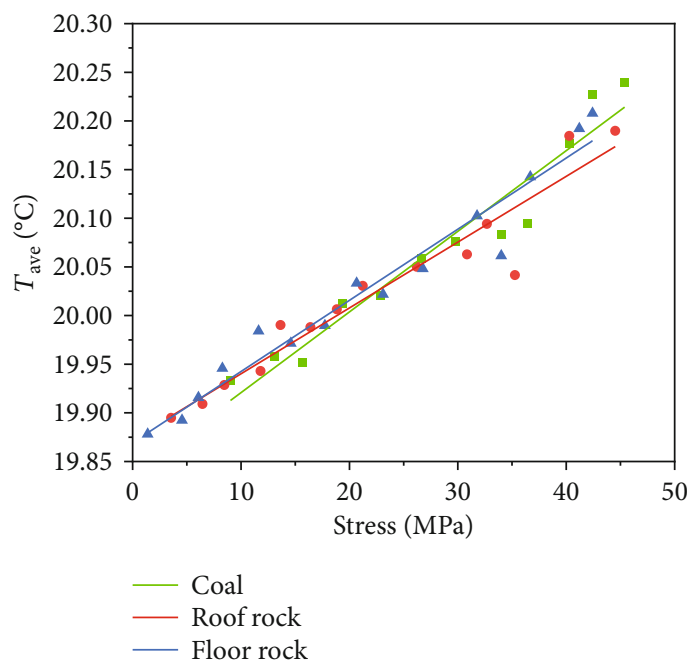

(c) Sample $11^{\#}$

FIGURE 12: The experimental fitting curve of thermal infrared radiation temperature and stress.

$T_{\text {ave }}$ reached the maximum value within a short time. Take sample $11^{\#}$ in Figure 10 (c) as an example for analysis.

For the coal body, in the initial fluctuation stage, the composite coal-rock, which is an anisotropic and heterogeneous material, has microdefects in the internal framework particles, and the internal microcracks and micropores gradually rupture and close at the initial stage of three-dimensional stress loading. Under the combined action of slight dislocation friction (the apparent damage has not yet begun) and the gas discharged from the pores, coal sample damage begins to occur, and there is a certain degree of heat dissipation. $T_{\text {ave }}$ decreases by $0.19^{\circ} \mathrm{C}$ within $0 \sim 19.7 \mathrm{~s}$. After entering stage of stress- keeping pressure, the internal stress field of the coal sample gradually stabilizes, and the damage is not severe at the beginning. At this time, the sample deforms in the elastic range, and the thermoelastic effect plays a leading role. After compaction, the particles in the coal body have a small range of friction, and the heat released causes the $T_{\text {ave }}$ fluctuation to rise again by $0.39^{\circ} \mathrm{C}$. In the linear heating stage, with the increase of stress, new cracks in the coal sample begin to develop, and microfractures appear and continue to develop. These microcracks continue to rub and heat up during the formation process and are accompanied by friction between the coal and rock interface. For heat production, $T_{\text {ave }}$ showed a linear 
fluctuation upward trend, and reached a local maximum of $20.52^{\circ} \mathrm{C}$ at $121.4 \mathrm{~s}$. During the local decline stage, the loadbearing structure of the coal sample began to fail, and different types of microfractures and thermal effects occurred inside. Under the combined action of shear cracks leading to heat generation and local thermal stress-induced local damage, the internal microcracks of the coal sample increase, and the external microcracks appear, which increases the sample volume and expands and absorbs heat. $T_{\text {ave }}$ shows a trend that first decreases from the local maximum and then stabilizes, decreasing by $0.43^{\circ} \mathrm{C}$ within $121.5 \mathrm{~s}$ to $152.2 \mathrm{~s}$. During the sudden temperature increase stage, since the confining pressure began to be unloaded at $152.2 \mathrm{~s}$, the confining pressure constraints on the sample gradually decreased, and the development of cracks and frictional slippage in the coal body became more and more intense. The deformation of the sample accelerates, the frictional heat effect occurs, and a large amount of heat is generated. $T_{\text {ave }}$ increases suddenly in a short time, reaching a global maximum of $20.81^{\circ} \mathrm{C}$ at $156.9 \mathrm{~s}$. At the same time, the expansibility of the mineral components in the coal gradually becomes prominent. The superimposed effect induces thermal stress inside the specimen, leading to aggravation of microfractures, the increase in volume is more significant, and some heat is absorbed, and $T_{\text {ave }}$ begins to show a downward trend again. In the fracture decline stage, after $180.7 \mathrm{~s}$, due to the further development of original cracks and the production of a large number of new cracks, they clustered towards the main rupture. When the stress reaches the maximum value of $45.46 \mathrm{MPa}$, the sample reaches the loadbearing limit, the cracks penetrate macroscopically in the coal body, and the sample ruptures. There was violent dislocation friction between the fractured surfaces, resulting in a large number of high-temperature points, and $T_{\text {ave }}$ had a small step increase, but the overall trend was still decreasing.

For the roof rock, with the initial load gradually increasing, the cracks and pores are in the compaction stage, the fracture surface does not have frictional heating effect, and the temperature fluctuates up and down. During the linear heating stage, a small amount of microscopic cracks also appeared in the roof rock. The $T_{\text {ave }}$ curve showed a nearly linear upward trend, but there was a buffer between 80 and $100 \mathrm{~s}$. $T_{\text {ave }}$ lags behind the coal body, reaching a local maximum of $20.28^{\circ} \mathrm{C}$ at $129.8 \mathrm{~s}$, which increased by about $0.14^{\circ} \mathrm{C}$. Due to the increase and expansion of internal microfractures, $T_{\text {ave }}$ starts to decrease from the local maximum, and reaches the global maximum at $20.70^{\circ} \mathrm{C}$ at $161.6 \mathrm{~s}$ later than the coal body after the confining pressure is unloaded and is lower than the maximum value of the $T_{\text {ave }}$ of the coal body.

The infrared radiation temperature change of the floor rock is similar to that of the roof rock. The difference is that the floor rock bears the gravity from the roof rock and the coal body. During the three-way stress loading stage and the stage of stress-keeping pressure, more gas is discharged from the internal voids, and the phenomenon of heat absorption phenomenon is obvious. The fluctuation trend of $T_{\text {ave }}$ is lower than that of the roof rock. In the linear heating stage, the temperature of the roof rock changes more obviously, the temperature is increased by $0.42^{\circ} \mathrm{C}$. And the occurrence time of the local maximum is between the coal body and the roof rock, reaching $20.31^{\circ} \mathrm{C}$ at $125.03 \mathrm{~s}$. Similarly, the global maximum reaches $20.73^{\circ} \mathrm{C}$ at $159.2 \mathrm{~s}$, which is between the $T_{\text {ave }}$ maximum of the coal body and the roof rock.

Figure 11 is the thermal imaging diagram of sample $11^{\#}$ during the loading and unloading process. Six time points of $20 \mathrm{~s}, 40 \mathrm{~s}, 90 \mathrm{~s}, 130 \mathrm{~s}, 160 \mathrm{~s}$, and $180 \mathrm{~s}$ are selected. It can be seen from the Figure 11 that the temperature change of the coal body during the loading and unloading process is more obvious. And the highest point of temperature is located in the middle axial area and the lower part of the coal body, and the temperature change range of the rock body is relatively small.

It can be seen from above that during the unloading and rupture process of the composite coal-rock, the $T_{\text {ave }}$ of the coal body appears earlier than the floor rock and the roof rock. In order to explore the precursory changes of infrared radiation temperature, only the $T_{\text {ave }}$ of the coal body can be compared with the stress peak time. Table 3 is a comparison of the peak arrival time and peak size of the average thermal infrared radiation temperature and stress on the coal surface under different unloading confining pressure rates for samples $1^{\#} \sim 15^{\#}$. The average thermal infrared radiation temperature peak arrival time of each sample is earlier than the stress peak arrival time. Combined with Figure 8, before the composite coal-rock is unstable and ruptured, the average thermal infrared radiation temperature of the roof rock, coal body, and floor rock exhibits a sudden increase and stepwise rise. Among them, the occurrence time of the precursors of the average thermal infrared radiation temperature of the coal body is ahead of the floor and roof rock, and the degree of change is the largest.

Table 4 shows the fitting equations and related parameters of some samples at different confining pressure unloading rates. The fitting curves of samples $1^{\#}, 6^{\#}$, and $11^{\#}$ are shown in Figure 12. It can be seen that the $T_{\text {ave }}$ has a good linear correlation with the stress, and the correlation coefficients are all above 0.90 . Compared with the fitting result in simulation, the correlation coefficient after experimental fitting is higher. This is the result of the large number of experimental sampling points and artificial points, which further proves that $T_{\text {ave }}$ has a good linear correlation with stress.

In summary, the experimental results show that the variation trend of the average thermal infrared radiation temperature on the surface of the sample is consistent with the simulation results. The average thermal infrared radiation temperature on the surface has a good correlation with the stress, which verifies the correctness of the simulation and analysis.

\section{Conclusions}

(1) Considering the combined effects of stress and thermal infrared radiation temperature on the unloading and rupture of anisotropic composite coal and rock, based on the basic theory of mechanics and the damage mechanics formula, it is deduced that the different components of the anisotropic composite coal and rock during the unloading and rupture process are at any arbitrary value. The relationship between 
thermal infrared radiation temperature and stress is averaged at all times, and a mathematical model of thermal-mechanical coupling under unloading and rupture conditions is established

(2) The simulation results show that under unloading conditions, the thermal infrared radiation temperature of the composite coal is concentrated in the coal seam. After $142.5 \mathrm{~s}$ unloading the confining pressure, the overall temperature field reaches the strongest. The greater the rate of unloading confining pressure, the shorter the peak arrival time of $T_{\text {ave }}$, and the larger the peak value. The $T_{\text {ave }}$ changes of roof rock, coal body, and floor rock are mainly divided into five stages, showing a trend of fluctuation, nearly linear rise, slow decline, and the sudden increase after unloading reaches the maximum and then slowly decreases

(3) The experimental results show that after $152.2 \mathrm{~s}$ of unloading the confining pressure, the constraints on the coal and rock gradually decrease, and the development of fissures and frictional slippage becomes more and more intense. The greater the rate of unloading confining pressure, the shorter the peak arrival time of thermal infrared radiation temperature and the greater the peak value. Among them, at $0.003 \mathrm{MPa} / \mathrm{s}$, $0.03 \mathrm{MPa} / \mathrm{s}$, and $0.05 \mathrm{MPa} / \mathrm{s}$ unloading confining pressure rates, the $T_{\text {ave }}$ of coal, floor rock, and roof rock increase suddenly before the stress peak reaches the maximum value, respectively: $20.69^{\circ} \mathrm{C}, 20.56^{\circ} \mathrm{C}$, $20.51^{\circ} \mathrm{C} ; 20.79^{\circ} \mathrm{C}, 20.70^{\circ} \mathrm{C}, 20.68^{\circ} \mathrm{C}$; and $20.81^{\circ} \mathrm{C}$, $20.73^{\circ} \mathrm{C}, 20.70^{\circ} \mathrm{C}$. The $T_{\text {ave }}$ of each component of the composite coal-rock has a good linear correlation with the stress, and the correlation coefficient is greater than 0.90 . The $T_{\text {ave }}$ variation law of composite coalrock under unloading conditions is consistent with the simulation results

The research results provide new ideas and new methods for monitoring and early warning of coal and rock dynamic disasters.

\section{Data Availability}

Test data used to support the findings of this study are available from the corresponding author upon request.

\section{Conflicts of Interest}

The authors declare no conflict of interest.

\section{Acknowledgments}

This work was supported by the discipline innovation team of Liaoning Technical University (LNTU20TD-29), Chinese National Natural Science Foundation (nos. 51604141 and 51204087), and Liaoning Provincial Education Committee Projects (LJ2019JL013 and LJ2020JCL020).

\section{References}

[1] X. Wu, Y. Peng, J. Xu, Q. Yan, W. Nie, and T. Zhang, "Experimental study on evolution law for particle breakage during coal and gas outburst," International Journal of Coal Science \& Technology, vol. 7, no. 1, pp. 97-106, 2020.

[2] B. Chen, "Stress-induced trend: the clustering feature of coal mine disasters and earthquakes in China," International Journal of Coal Science \& Technology, vol. 7, no. 4, pp. 676-692, 2020.

[3] W. J. Yao, J. Y. Pang, Q. Y. Ma, and H. Lyimo, "Influence and sensitivity analysis of thermal parameters on temperature field distribution of active thermal insulated roadway in high temperature mine," International Journal of Coal Science \& Technology, vol. 8, no. 1, pp. 47-63, 2021.

[4] J. Lu, G. Z. Yin, H. Gao, M. H. Li, and B. Deng, "Sure relief of gas-bearing coal under true triaxial loading," Journal of China Coal Society, vol. 45, no. 5, pp. 1812-1823, 2020.

[5] F. R. Huang, S. X. Yan, A. Li, and P. C. Jiang, "Experimental study on infrared radiation of rock under uniaxial compression," Journal of North China University of Science and Technology (Natural Science Edition), vol. 42, no. 4, pp. 24-29, 2020.

[6] S. D. Wang and W. Y. Hu, "Research on coal and rock mass temperature fields characteristics and control factors in deep mine," Coal Science and Technology, vol. 41, no. 8, pp. 18-21, 2013.

[7] F. Q. Gao, H. P. Kang, and L. Yang, "Experimental and numerical investigations on the failure processes and mechanisms of composite coal-rock specimens," Scientific reports, vol. 10, no. 1, p. 13422, 2020.

[8] Y. Tao, L. Zhenhua, C. Zhiheng, Z. Quanle, C. Jialin, and H. Yanbo, "Deformation and failure characteristics of composite coal mass," Environmental Earth Sciences, vol. 80, no. 3, 2021.

[9] Z. L. Zhao, K. Zhao, and X. Wang, "Study on mechanical characteristics and damage evolution law of coal-rock-like under different loading rates," Coal science and technology, vol. 45, no. 10, pp. 41-47, 2017.

[10] Y. L. Tan and Y. B. Zhang, Research on Impact Characteristics of Inclined Coal-Rock Composite Body, Kemerovo, Russia, 2016.

[11] L. Q. Ma and H. Sun, "Spatial-temporal infrared radiation precursors of coal failure under uniaxial compressive loading," Infrared Physics \& Technology, vol. 93, pp. 144-153, 2018.

[12] L. Ma, H. Sun, Y. Zhang, T. Zhou, K. Li, and J. Guo, "Characteristics of infrared radiation of coal specimens under uniaxial loading," Rock Mechanics and Rock Engineering, vol. 49, no. 4, pp. 1567-1572, 2016.

[13] Z. Li, S. Yin, Y. Niu et al., "Experimental study on the infrared thermal imaging of a coal fracture under the coupled effects of stress and gas," Journal of Natural Gas Science and Engineering, vol. 55, pp. 444-451, 2018.

[14] G. Q. Chen, Y. S. Pan, G. Z. Zhang, G. Z. Zhang, and D. Wang, "Thermal infrared precursor information of crack propagation for rock bridges," Chinese Journal of Geotechnical Engineering, vol. 41, no. 10, pp. 1817-1826, 2019.

[15] M. C. He, W. L. Gong, D. J. Li, and H. M. Zhai, "Physical modeling of failure process of the excavation in horizontal strata based on IR thermography," Mining Science and Technology, vol. 19, no. 6, pp. 689-698, 2009. 
[16] W. L. Gong, Y. X. Gong, and A. F. Long, "Multi-filter analysis of infrared images from the excavation experiment in horizontally stratified rocks," Infrared Physics and Technology, vol. 56, pp. 57-68, 2013.

[17] C. Wang, Z. Lu, L. Liu, X. Chuai, and H. Lu, "Predicting points of the infrared precursor for limestone failure under uniaxial compression," International Journal of Rock Mechanics and Mining Sciences, vol. 88, pp. 34-43, 2016.

[18] F. T. Freund, "Rocks that crackle and sparkle and glow: strange pre-earthquake phenomena," Society for Scientific Exploration, vol. 17, no. 1, pp. 37-71, 2003.

[19] S. J. Liu, Y. B. Zhang, L. X. Wu, G. L. Li, and Q. L. Chen, "Infrared radiation characteristics of concrete fracture and water seepage process," Journal of rock mechanics and engineering, vol. 28, no. 1, pp. 53-58, 2009.

[20] W. Q. Guo, Y. J. Zhang, and L. Q. An, “Test on infrared radiation exploration technology to predict mine bum ping pressure," Coal science and technology, vol. 35, no. 1, pp. 73-77, 2007.

[21] Z. J. Xu, Q. X. Qi, and H. Y. Li, "Study on infrared radiation characteristics of loading failure of impact prone coal," Chinese Journal of safety science, vol. 23, no. 10, pp. 121-125, 2013.

[22] Y. B. Zhang, Z. Yang, and X. L. Yao, "Experimental study on real time early warning method of roadway rock burst based on temporal and spatial evolution of infrared radiation," Journal of mining and safety engineering, vol. 35, no. 2, pp. 299307, 2018.

[23] L. Q. MA, Y. Zhang, H. SUN, S. K. Wang, and A. Najeem, "Experimental study on the control effect of stress on infrared radiation during coal rock fracture," Chinese journal of coal and rock, vol. 42, no. 1, pp. 140-147, 2017.

[24] F. Q. Cheng, Z. H. Li, and Y. Wei, "Damage evolution characteristics of coal rock based on uniaxial compression infrared radiation," Industrial and mining automation, vol. 44, no. 5, pp. 64-70, 2018.

[25] Z. Yang, Q. J. Qi, D. D. Ye, X. Li, and H. Luo, "The change of infrared radiation temperature inside the fracture of composite coal rock under load," Journal of China Coal Society, vol. 41, no. 3, pp. 618-624, 2016.

[26] X. P. Lai, X. M. Liu, and P. F. Shan, "Study on thermal infrared radiation variation of fractured coal-rock mass failure during mining," Journal of Mining and Safety Engineering, vol. 36, no. 4, pp. 777-785, 2019.

[27] X. Li, Z. Yang, S. Dai, B. Qiu, and Y. Xin, "Variation of infrared radiation temperature on fracture surface of loaded composite coal rock," Chinese journal of safety science, vol. 27, no. 1, pp. 110-115, 2017.

[28] K. Du, X. B. Li, D. Y. Li, and L. Weng, "Failure properties of rocks in true triaxial unloading compressive test," Transactions of Nonferrous Metals Society of China, vol. 25, no. 2, pp. 571-581, 2015.

[29] F. Du, K. Wang, G. Wang, Y. Jiang, C. Xin, and X. Zhang, "Investigation of the acoustic emission characteristics during deformation and failure of gas-bearing coal-rock combined bodies," Journal of Loss Prevention in the Process Industries, vol. 55, pp. 253-266, 2018.

[30] Y. L. Feng and W. J. Ju, "Study on mechanical characteristics and damage failure of coal mass from roadway side wall under loading and unloading stress path," Coal Science and Technology, vol. 47, no. 4, pp. 210-217, 2019.
[31] J. W. Zhang, F. Z. Li, X. H. Yu, H. Ding, and L. H. Kong, "Research on evolution characteristics of early-age temperature-stress field of inner lining at deep frozen shaft," Coal Science and Technology, vol. 49, no. 2, pp. 69-76, 2021.

[32] Y. L. Lu, L. G. Wang, F. R. Tang, and Y. He, "Fracture evolution of overburden rock in the combustion zone under the action of temperature-stress coupling during underground coal gasification," Chinese journal of coal and coal, vol. 37, no. 8, pp. 1292-1298, 2012.

[33] F. Du and K. Wang, "Unstable failure of gas-bearing coal-rock combination bodies: insights from physical experiments and numerical simulations," Process Safety and Environmental Protection, vol. 129, pp. 264-279, 2019.

[34] D. P. Shi, "Study on coal and rock damage under multiphase coupling," Scientific Journal of Intelligent Systems Research, vol. 2, no. 12, pp. 135-137, 2020.

[35] H. D. Chen, Y. P. Cheng, Y. B. Pu, H. X. Zhou, and Q. Q. Liu, "Study on reconstituted coal damage features during unloading process," Coal Science and Technology, vol. 41, no. 3, pp. 84-87, 2013.

[36] Y. Y. Du, H. Sun, and L. Q. Ma, "Infrared radiation response characteristics in coal damage evolution process," Coal science and technology, pp. 1-9, 2021.

[37] Q. S. Liu, K. D. Liu, J. B. Zhu, and X. L. Lu, "Study of mechanical properties of raw coal under high stress with triaxial unloading," Chinese Journal of Rock Mechanics and Engineering, vol. 33, no. 1, pp. 24-34, 2014.

[38] S. Y. Chen, L. Q. Liu, P. X. Liu, J. Ma, and G. Q. Chen, "Theoretical and experimental study on the relationship between stress-strain and temperature response," SCIENCE IN CHINA PRESS, vol. 39, no. 10, pp. 1446-1455, 2009.

[39] C. H. Wang and X. J. Shi, "Finite element analysis of effect of temperature variation on temperature stress in mass concrete," Building Construction, vol. 30, no. 6, pp. 442-444, 2008.

[40] W. C. Zhu, C. H. Wei, J. Tian, T. H. Yang, and C. A. Tang, "Coupled thermal-hydraulie-mechanical model during rock damage and its preliminary application," Rock and Soil Mechanics, vol. 30, no. 12, pp. 3851-3857, 2009.

[41] G. J. Zhang and Y. Zhang, "Partition failure characteristics of rock material loading and unloading based on MohrCoulomb criterion," Journal of China Coal Society, vol. 44, no. 4, pp. 1049-1058, 2019.

[42] M. C. He and P. Y. Guo, "Deep rock mass thermodynamic effect and temperature control measures," Chinese Journal of Rock Mechanics and Engineering, vol. 32, no. 12, pp. 23772393, 2013.

[43] G. Y. Hou, H. Y. Jing, and J. P. Liang, "Experimental study on deformation and acoustic emission characteristics of rectangular roadway under different unloading rates," Rock and Soil Mechanics, vol. 40, no. 9, 2019.

[44] Y. J. Qian, Y. L. Wu, W. W. Pei, and Y. Y. Zhu, "Rock strength and deformation characteristics under different unloading," Hydro-Science and Engineering, vol. 6, pp. 48-54, 2020.

[45] X. Li, H. Li, Z. Yang et al., "Experimental study on triaxial unloading failure of deep composite coal-rock," Advances in Civil Engineering, vol. 2021, 2021. 